\title{
Phosducin influences sympathetic activity and prevents stress-induced hypertension in humans and mice
}

\author{
Nadine Beetz, ${ }^{1}$ Michael D. Harrison, ${ }^{2,3}$ Marc Brede, ${ }^{4}$ Xiangang Zong, ${ }^{5}$ Michal J. Urbanski, ${ }^{1}$ \\ Anika Sietmann, ${ }^{6}$ Jennifer Kaufling, ${ }^{7}$ Michel Barrot, ${ }^{7}$ Mathias W. Seeliger, ${ }^{8}$ \\ Maria Augusta Vieira-Coelho, ${ }^{9}$ Pavel Hamet, ${ }^{10,11}$ Daniel Gaudet, ${ }^{10,12}$ Ondrej Seda, ${ }^{11}$ \\ Johanne Tremblay, ${ }^{10,11}$ Theodore A. Kotchen, ${ }^{13}$ Mary Kaldunski, ${ }^{3}$ Rolf Nüsing, ${ }^{14}$ Bela Szabo, ${ }^{1}$ \\ Howard J. Jacob, ${ }^{2,3}$ Allen W. Cowley Jr., ${ }^{3}$ Martin Biel, ${ }^{5}$ Monika Stoll, ${ }^{6}$ Martin J. Lohse, ${ }^{4}$ \\ Ulrich Broeckel,2,3,13,15 and Lutz Hein'1
}

\begin{abstract}
${ }^{1}$ Institute of Experimental and Clinical Pharmacology and Toxicology and Centre for Biological Signalling Studies, Albert-Ludwigs-University Freiburg, Freiburg, Germany. ${ }^{2 H u m a n}$ and Molecular Genetics Center and ${ }^{3}$ Department of Physiology, Medical College of Wisconsin, Milwaukee, Wisconsin, USA. ${ }^{4}$ Institute of Pharmacology and Toxicology, University of Würzburg, Würzburg, Germany. ${ }^{5}$ Department of Pharmacy, Center for Drug Research, and Center for Integrated Protein Science Munich, Ludwig-Maximilians-University, München, Germany. ${ }^{6}$ Leibniz Institute for Arteriosclerosis Research, University of Münster, Münster, Germany. ${ }^{7}$ Institut des Neurosciences Cellulaires et Intégratives, Centre National de la Recherche Scientifique, Strasbourg, France. ${ }^{8}$ Division of Ocular Neurodegeneration, Institute for Ophthalmic Research, Centre for Ophthalmology, Universitätsklinikum Tübingen, Tübingen, Germany. 9 Institute of Pharmacology and Therapeutics, University of Porto, Porto, Portugal. ${ }^{10}$ University of Montreal, Montréal, Quebec, Canada.

${ }^{11}$ Centre Hospitalier de I'Université de Montréal, Montréal, Quebec, Canada. ${ }^{12}$ Chicoutimi Hospital, Chicoutimi, Quebec, Canada. ${ }^{13}$ Department of Medicine, Medical College of Wisconsin, Milwaukee, Wisconsin, USA. ${ }^{14}$ Institute of Clinical Pharmacology, University of Frankfurt, Frankfurt, Germany.

${ }^{15}$ Department of Pediatrics, Medical College of Wisconsin, Milwaukee, Wisconsin, USA.
\end{abstract}

\begin{abstract}
Hypertension and its complications represent leading causes of morbidity and mortality. Although the cause of hypertension is unknown in most patients, genetic factors are recognized as contributing significantly to an individual's lifetime risk of developing the condition. Here, we investigated the role of the $\mathrm{G}$ protein regulator phosducin $(\mathrm{Pdc})$ in hypertension. Mice with a targeted deletion of the gene encoding $\mathrm{Pdc}\left(\mathrm{Pdc}^{-/-}\right.$mice) had increased blood pressure despite normal cardiac function and vascular reactivity, and displayed elevated catecholamine turnover in the peripheral sympathetic system. Isolated postganglionic sympathetic neurons from $P d c^{-/-}$mice showed prolonged action potential firing after stimulation with acetylcholine and increased firing frequencies during membrane depolarization. Furthermore, $P d c^{-/-}$mice displayed exaggerated increases in blood pressure in response to post-operative stress. Candidate gene-based association studies in 2 different human populations revealed several SNPs in the PDC gene to be associated with stress-dependent blood pressure phenotypes. Individuals homozygous for the G allele of an intronic PDC SNP (rs12402521) had 12-15 mmHg higher blood pressure than those carrying the A allele. These findings demonstrate that PDC is an important modulator of sympathetic activity and blood pressure and may thus represent a promising target for treatment of stress-dependent hypertension.
\end{abstract}

\section{Introduction}

Hypertension and its cardiovascular consequences contribute to the leading causes of morbidity and mortality worldwide (1). In over $90 \%$ of hypertensive patients, the causes of increased blood pressure are unknown. Thorough clinical investigation may help to identify metabolic or endocrine causes, tumors, or other treatable conditions that contribute to the development of secondary hypertension in less than $10 \%$ of individuals. The remaining majority of patients in whom no cause can be found are diagnosed with primary, or "essential," hypertension (2). Besides environmental factors, a significant portion of the risk for hypertension is determined by genetic factors (3). There is increasing evidence that many forms of hypertension are initiated and maintained by elevated activity of the sympathetic system $(4,5)$. However, the molecular mechanisms underlying sympathetic activation in essential hypertension are largely unknown.

Cardiovascular function is modulated by signals, hormones, and transmitters that activate $G$ protein-coupled receptors (6),

Conflict of interest: The authors have declared that no conflict of interest exists. Citation for this article: J. Clin. Invest. 119:3597-3612 (2009). doi:10.1172/JCI38433.
$\mathrm{G}$ proteins (7), and $\mathrm{G}$ protein regulators (8). Thus, we hypothesized that phosducin (Pdc), which was identified in retina and brain as a $33-\mathrm{kDa}$ protein and binds to the $\beta \gamma$ subunits of heterotrimeric GTP-binding proteins $(9,10)$, might affect cardiovascular homeostasis. Despite the fact that Pdc and its homologs have been shown to regulate several aspects of $G$ protein-coupled receptor signaling, gene transcription, and protein folding and degradation $(11-14)$, its physiologic role in vivo is largely unknown. Here we demonstrate that mice deficient in Pdc develop significant stress-dependent hypertension due to increased sympathetic tone. In order to test whether PDC may also affect blood pressure in humans, we performed a candidate-gene association analysis in 2 populations of French-Canadian (FC) and African-American (AA) origin. $P D C$ was significantly associated with both wake and stress-response blood pressure phenotypes. FC and AA individuals showed a 15- and 12-mmHg difference, respectively, in wake systolic blood pressure (SBP) between the 2 homozygous versions of a single nucleotide polymorphism in $P D C$. Taken together, we believe that both human and animal studies establish $P D C$ as a novel hypertension gene. Modulating the function of PDC may 
A Phosducin gene $(P d c)$
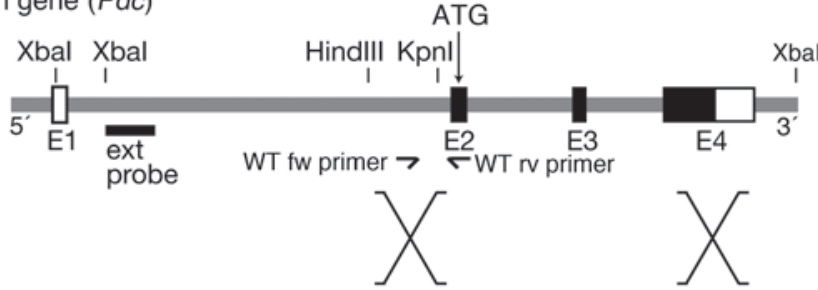

Targeting vector

plasmid

HindIII Kpnl Xbal

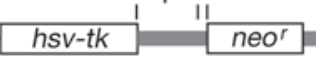

Disrupted allele

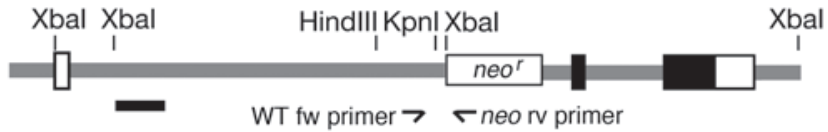

B
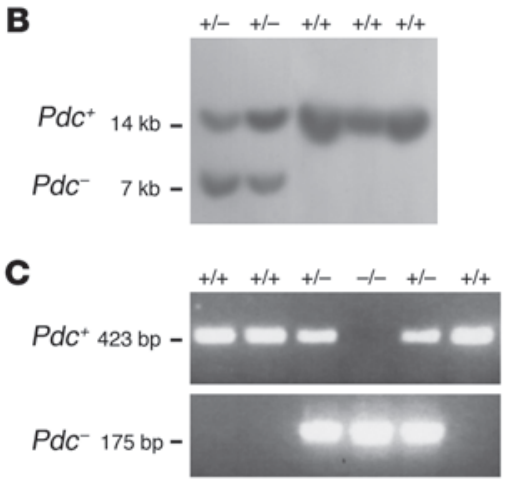

D

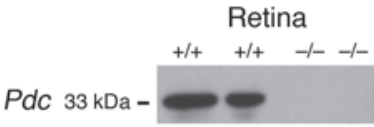

E
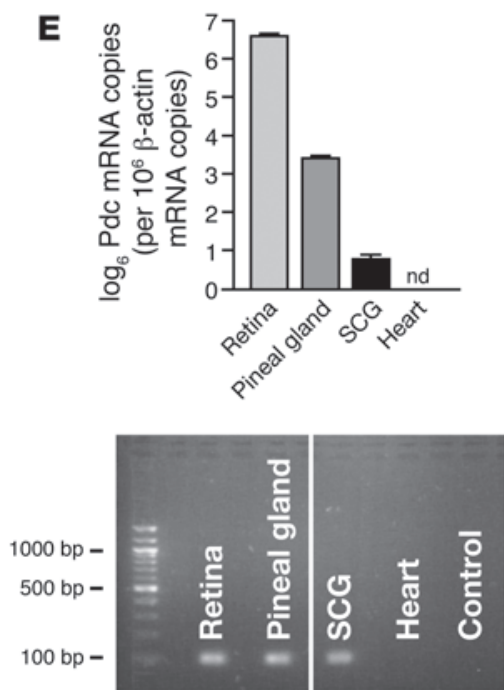

\section{Figure 1}

Generation of mice deficient in Pdc. (A) Targeting vector for disruption of $P d c$ in mouse ES cells via homologous recombination. Insertion of a neomycin resistance gene $\left(\right.$ neo $\left.^{r}\right)$ disrupted the exon 2 (E2) of the $P d c$ gene including the start codon. Fw, forward primer; rv, reverse primer; ATG, position of the start codon of the Pdc gene. (B) Southern blot analysis of E14 mouse ES cells transfected with the $P d c$ targeting vector. Using a 5 ' external probe, the wild-type allele $(+/+)$ was identified as a 14-kb band, whereas the targeted allele $(+/-)$ was detected as a 7-kb signal (after incubation of genomic DNA with Xbal). (C) Identification of wild-type or deleted Pdc alleles (+/-, -l-) by PCR analysis of genomic DNA obtained from tail biopsies of mice. (D) Absence of Pdc protein in retina of $P \mathrm{Pc}^{-/-}$mice as confirmed by Western blotting with a polyclonal Pdc antiserum. (E) Top: Quantitative PCR analysis of $P d c$ mRNA levels in wildtype retina, pineal gland, SCG, and cardiac ventricles ( $P d c$ mRNA copy number normalized to $10^{6}$ Actb mRNA copies, $n=3-5$ per group). Bottom: $\mathrm{PCR}$ reactions in the plateau phase were loaded on a $2 \%$ agarose gel to verify PCR product size (106 bp) (lanes were run on the same gel but were noncontiguous). nd, not detectable. (F) The identity of the PCR products from SCG was verified by subcloning and sequencing, which identified a sequence corresponding to amino acids $25-55$ in $\mathrm{Pdc}$ (circle, black ribbon part in Pdc structure).
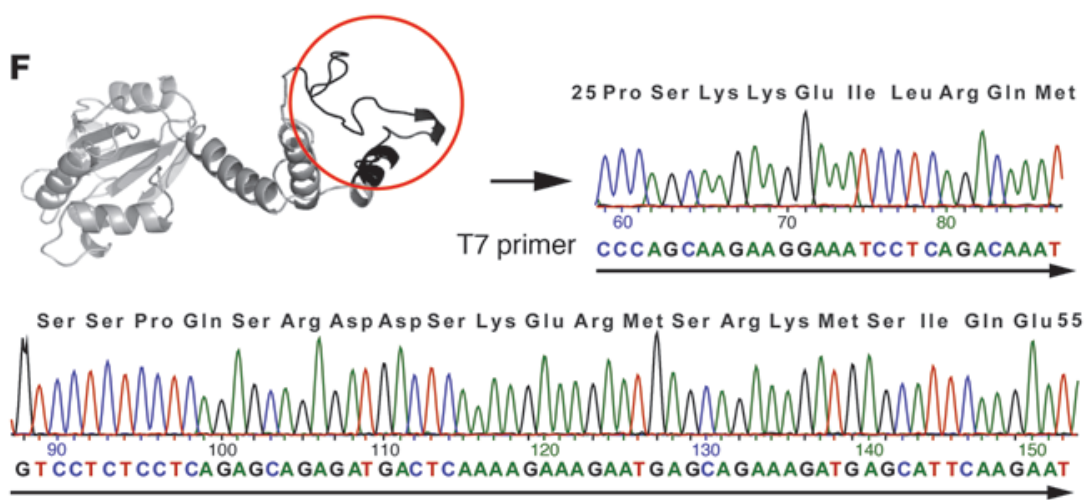

Phosducin (106 bp PCR product)

represent a novel mechanism to control sympathetic activity and to treat stress-induced hypertension without adversely affecting resting blood pressure.

\section{Results}

Generation of Pdc-deficient mice. To obtain Pdc-deficient mice, the murine $P d c$ gene was disrupted by gene targeting (Figure $1, A-C$ ). Mice lacking 1 or 2 copies of the $P d c$ gene were viable and fertile and developed normally. Pdc protein was completely absent in the retina of $P d c^{-1-}$ mice (Figure 1D). By means of Western blotting, quantitative RT-PCR, and a branched DNA assay we detected Pdc protein and mRNA in different adult wild-type tissues including retina, pineal gland, and sympathetic ganglia but not in the heart (Figure 1E), blood vessels, or kidney (data not shown). The presence of Pdc in RT-PCR products was verified by sequencing (Figure 1F). Heterozygous $P d c$ deletion led to a $51 \% \pm 9 \%$ reduction in $P d c$ 
A

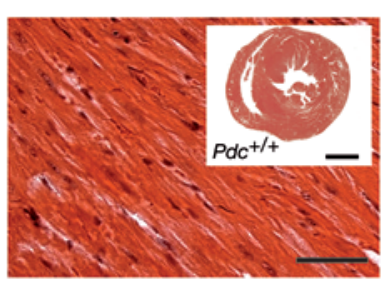

B
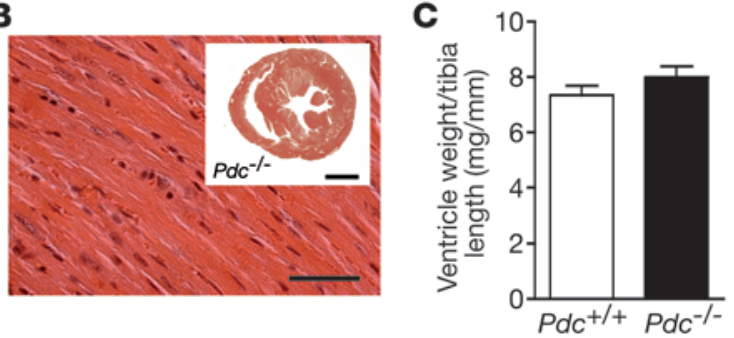

D

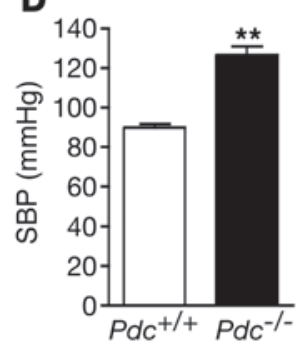

E

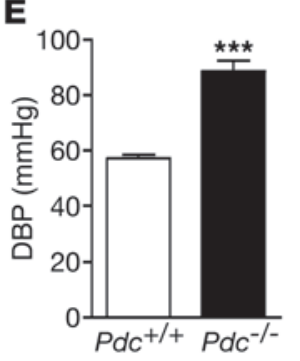

$\mathbf{F}$

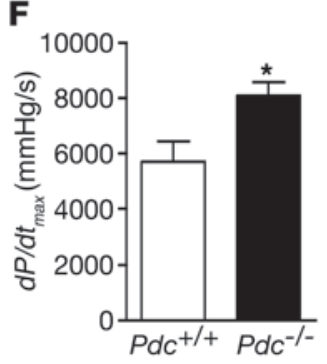

G
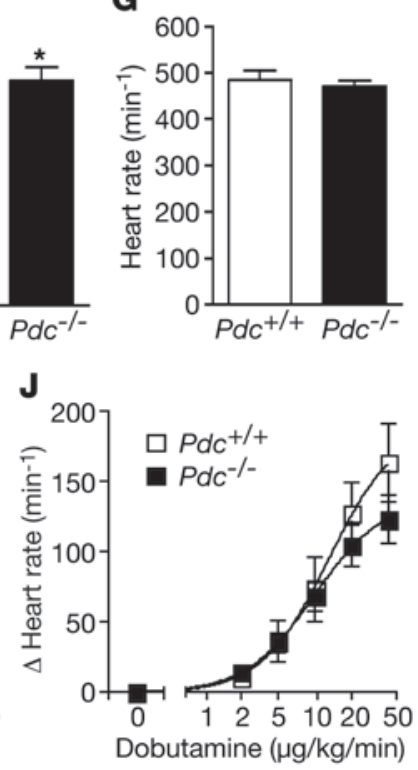

\section{Figure 2}

Pdc-deficient mice have increased blood pressure. (A and $\mathbf{B}$ ) Midequatorial cross-sections through the hearts of wild-type (A, inset) or $\mathrm{PdC}^{-/-}$mice (B, inset) did not reveal microscopic alterations in $\mathrm{PdC}^{-/-}$hearts (H\&E staining). Scale bars: $50 \mu \mathrm{m}$ (A and B); 0.5 $\mathrm{mm}$ (insets). (C) Heart weight/ tibia length ratios did not differ between $\mathrm{Pdc}^{+/+}$and $\mathrm{Pdc}^{-/}$mice (age 1.5-2 months, $n=6-10$ per genotype; $P=0.213$ ). (D-G) During isoflurane anesthesia, arterial and left ventricular catheterization with a microtip catheter revealed increased SBP and DBP and $d P / d t_{\text {max }}$ in $P d c^{-/-}$mice $(n=8$ per genotype group). ${ }^{*} P<0.05$, ${ }^{\star *} P<0.01,{ }^{* * *} P<0.001$. $(\mathbf{H}-\mathbf{J})$ Infusion i.v. of norepinephrine or dobutamine in anesthetized mice did not reveal differences in hemodynamic response between genotypes ( $n=6-11$ per genotype).
mRNA and a $12 \% \pm 1 \%$ decrease in Pdc protein expression in the retina compared with $P d c^{+/+}$specimens (data not shown).

Cardiac morphology and function of Pdc-deficient mice. Expression of $\mathrm{Pdc}$ in sympathetic ganglia indicated that Pdc may play a role in cardiovascular regulation. Thus, we initially investigated cardiac morphology and hemodynamic function of Pdc-deficient mice. Cardiac gross anatomy, heart weight, and histology did not differ between $P d c^{-/-}$and $P d c^{+/+}$mice at an early age of 1.5-2 months (Figure $2, \mathrm{~A}-\mathrm{C})$. Upon catheterization of the aorta and left ventricle using a microtip catheter, SBP and diastolic blood pressure (DBP) as well as left ventricular contractility $\left(d P / d t_{\max }\right)$ were significantly elevated in $P d c^{-/-}$compared with $P d c^{+/+}$mice (SBP $P d c^{-/-} 126.4 \pm 4.3$ mmHg vs. $P d c^{+/+} 89.8 \pm 2.0 \mathrm{mmHg} ; P<0.01$; Figure $\left.2, \mathrm{D}-\mathrm{F}\right)$. Resting heart rate did not differ between genotypes (Figure $2 \mathrm{G}$ ). In order to test whether hypertension in $P d c^{-1-}$ mice was due to increased sensitivity to adrenergic stimulation, the adrenoceptor agonists norepinephrine and dobutamine were applied by i.v. infusion in anesthetized mice (Figure 2, H-J). Activation of $\alpha_{1}$ and $\beta_{1}$ adrenoceptors by norepinephrine caused similar increases in mean arterial pressure (Figure $2 \mathrm{H}$ ) and heart rate (data not shown) in both groups of mice. Dobutamine, which primarily activates cardiac $\beta_{1}$ adrenoceptors, had identical positive inotropic and positive chronotropic effects in $\mathrm{Pdc}^{-/-}$and $\mathrm{Pdc^{+/+ }}$ mice (Figure 2, I and J). Taken together, these results indicate that deletion of the $P d c$ gene causes hypertension without primarily affecting cardiac function in young mice.

Vascular function of Pdc-deficient mice. In order to determine whether hypertension was due to increased vasoconstriction or vascular remodeling, arterial vascular function was assessed in a small vessel myograph in vitro (Figure 3). Histological analysis of isolated vessel segments from mouse iliac arteries at young adult age (1.5-2 months) did not reveal any structural changes of the intima, media, or adventitia (Figure 3, A and B). Media thickness or smooth muscle cell cross-sectional areas did not differ between iliac arteries isolated from wild-type or Pdc-deficient mice (Figure 3, $\mathrm{C}$ and D). After mounting vessel segments from the iliac artery of $P d c^{+/+}$and $P d c^{-/-}$mice in a myograph, internal vessel diameters set to a pretension corresponding to an intraluminal pressure of $100 \mathrm{mmHg}$ were identical between genotypes (Figure 3E). Contractile responses elicited by potassium depolarization or the $\alpha_{1}$ adrenoceptor agonist phenylephrine were not altered in Pdc-deficient vessels (Figure 3F). Furthermore, the muscarinic agonist carbachol induced similar endothelium-dependent relaxation in arteries from $\mathrm{Pdc}^{+/+}$and $\mathrm{Pdc}^{-/-}$mice (Figure 3G). Similar results were obtained with vessel segments isolated from the abdominal aorta or mesenteric artery (data not shown). Histological investigation of arteries and capillary density in the hindlimb did not reveal differences between genotypes (data not shown). Thus, in addition to cardiac function, vasoconstriction and vasorelaxation of isolated arteries was not affected by deletion of the $P d c$ gene at a young age. Moreover, we did not identify any differences in renal development, histology, or function between genotypes that may have affected blood pressure regulation (data not shown). Neither plasma renin activity nor plasma levels of angiotensin peptides or aldosterone were elevated in Pdc-deficient mice (data not shown). $P d c^{-/-}$mice show stress-dependent hypertension. In order to further dissect the mechanism of hypertension in response to $P d c$ ablation, 

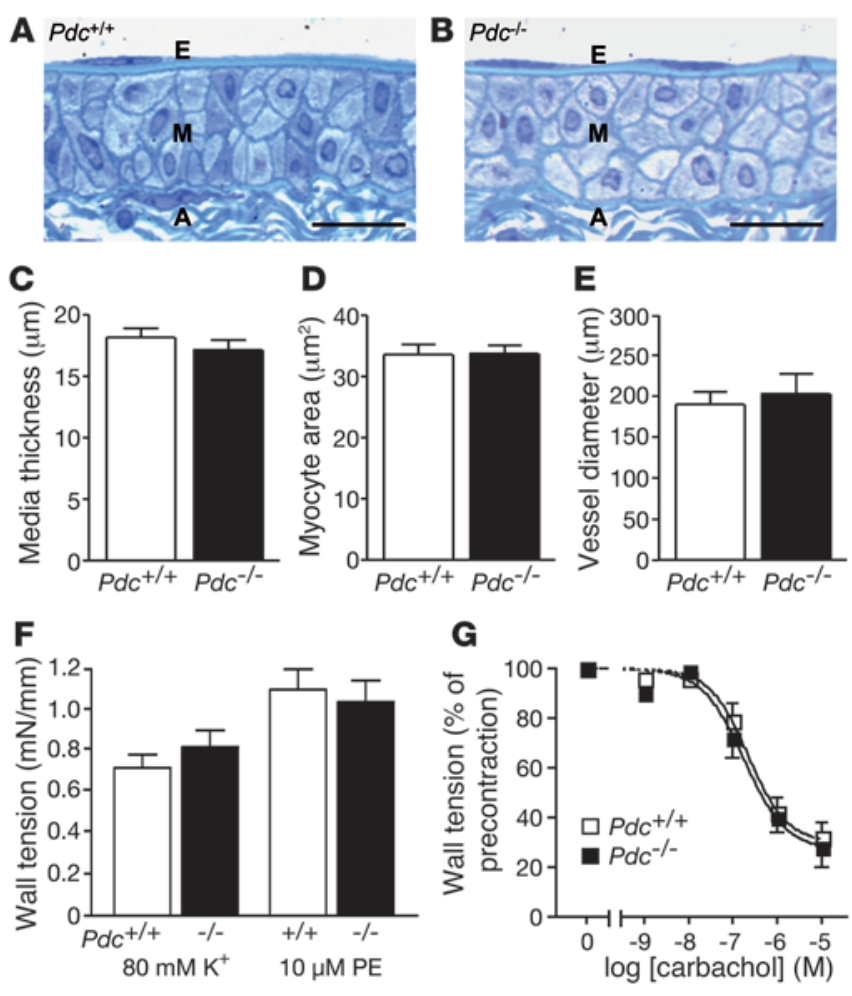

telemetric pressure transducers were implanted into the carotid or femoral arteries of $P d c^{+/+}$and $P d c^{-/}$mice. Two weeks after implantation of the telemetry devices, circadian rhythm was present in both strains of mice (Figure 4, A and B). However, nighttime arterial SBPs and DBPs were significantly higher in $P d c^{-/-}$mice compared with $\mathrm{Pdc}^{+/+}$mice (Figure 4, A-D). Heart rate did not differ between genotypes (Figure 4E).

Postoperative stress or transfer of mice into novel environments elicited greater increases in blood pressure in $\mathrm{Pdc}^{-/-}$than in $\mathrm{Pdc^{+/+ }}$ mice (Figure 4, F-K). During the first 12 hours of recovery from anesthesia after implantation of telemetric devices, SBP reached $180 \mathrm{mmHg}$ in $\mathrm{Pdc^{-/ }}$ mice, whereas it remained around $140 \mathrm{mmHg}$ in $\mathrm{Pdc}^{+/+}$mice (Figure 4F). We observed a gene-dosage effect, as postoperative blood pressure was already increased in mice with only 1 deleted copy of the $P d c$ gene ( $P d c^{+/-}$; Figure 4, F and G). Furthermore, hypertension was elicited by stress induced by transfer of mice into empty cages that had previously been used by other male mice (Figure 4, I and J). SBP increased by $57 \pm 3 \mathrm{mmHg}$ in $\mathrm{Pdc}^{-/}$ mice compared with $37 \pm 4 \mathrm{mmHg}$ in $P d c^{+/+}$mice (Figure 4, I and J). Heart rates during recovery from anesthesia or cage switching did not differ between $\mathrm{Pdc}^{-/-}$and $\mathrm{Pdc^{+/+ }}$ mice (Figure 4, $\mathrm{H}$ and $\mathrm{K}$ ). Acute blockade of vasoconstrictory $\alpha_{1}$ adrenoceptors by prazosin lowered SBPs and DBPs to similar levels in awake, freely moving $\mathrm{Pdc}^{+/+}$and $P d c^{-/}$mice (Figure 4, L and $\mathrm{M}$ ), providing evidence that enhanced sympathetic tone elicited hypertension in Pdc-deficient mice.

In order to exclude a possible contribution of Pdc in the retina or pineal gland for blood pressure regulation, several conditions were tested (Supplemental Table 1; supplemental material available online with this article; doi:10.1172/JCI38433DS1). The targeted $\mathrm{Pdc}$ allele was crossed onto a $\mathrm{C} 3 \mathrm{H} / \mathrm{HeN}$ mouse background for 2 reasons. First, we wanted to prove that Pdc ablation caused hypertension in mice irrespective of the genetic background. Second, we wanted to address whether hypertension would also occur in a

\section{Figure 3}

Vascular function in Pdc-deficient mice at a young age. (A-D) Longitudinal sections through the iliac artery of wild-type (A) and $P d c^{-/}$mice (B) revealed no alterations in microscopic structure, media thickness $(\mathbf{C})$, or vascular smooth muscle cell cross-sectional area (D) in $\mathrm{Pdc}^{-/}$mice $(n=4$ per genotype, age 1.5-2 months). Scale bars: $20 \mu \mathrm{m}$. E, endothelium; $\mathrm{M}$ media layer; A, adventitia. (E) Internal diameter of isolated iliac artery segments mounted in a small vessel myograph and prestretched to a wall tension corresponding to $100 \mathrm{mmHg}$ intraluminal pressure $(n=6$ per genotype). (F) Vasoconstrictory response to depolarization by 80 $\mathrm{mM} \mathrm{K}^{+}$or $\alpha_{1}$ adrenoceptor activation by phenylephrine was similar in $P d c^{-/}$and $P d c^{+/+}$iliac artery segments $(n=6-10)$. (G) Vasorelaxation induced by the muscarinic receptor agonist carbachol was unaltered in $\mathrm{Pdc}^{-/-}$compared with $\mathrm{Pdc} \mathrm{c}^{+/+}$vessels. Vessel segments were precontracted by $10 \mu \mathrm{M}$ phenylephrine ( $n=6$ vessels per genotype).

melatonin-deficient mouse strain (C57BL/6J) versus a melatoninproficient strain $(\mathrm{C} 3 \mathrm{H} / \mathrm{HeN})(15)$. On the $\mathrm{C} 3 \mathrm{H} / \mathrm{HeN}$ background, $P d c^{-/-}$mice still showed significant postoperative hypertension

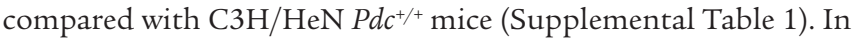
order to investigate whether modulation of endogenous melatonin production by external light conditions affects the postoperative hypertensive response, mice were maintained for 2 weeks under long daylight (20-hour light/4-hour dark) or long night (4-hour light/20-hour dark) conditions. However, external lighting conditions did not affect postoperative hypertension in $\mathrm{Pdc}^{-/-}$or $P d c^{+/+}$mice (Supplemental Table 1). Furthermore, genetic ablation of melatonin signaling in $\mathrm{MT}_{1 \mathrm{a}} / \mathrm{MT}_{1 \mathrm{~b}}$ melatonin receptor-deficient mice did not induce significant postoperative hypertension (Supplemental Table 1). Taken together, these results indicate that external light/dark cycles do not affect stress-dependent hypertension in Pdc-deficient mice.

Increased sympathetic activity in $\mathrm{Pdc}^{-/-}$mice. To further elucidate the underlying mechanism of stress-induced hypertension in $P d c^{-1-}$ mice, we determined the activity of the sympathetic nervous system and found strong evidence for sympathetic activation in $\mathrm{Pdc}^{-/-}$mice (Figure 5). In arterial blood samples collected during isoflurane-induced anesthesia, norepinephrine levels were 3.4-fold higher in $\mathrm{Pdc}^{-/-}$than in $\mathrm{Pdc^{+/+ }}$ mice (Figure 5B), while the concentration of circulating epinephrine was not altered (Figure 5C). Renal elimination of norepinephrine was significantly higher in $\mathrm{Pdc}^{-/-}$than in $\mathrm{Pdc^{+/+ }}$ mice during the night but not during the day (Figure 5D). Furthermore, pre- and postsynaptic metabolites of norepinephrine, dihydroxyphenylglycol (DHPG) and normetanephrine $(\mathrm{NMN})$ were significantly increased in cardiac tissue from $P d c^{-/-}$compared with $P d c^{+/+}$mice (Figure 5, E and $\mathrm{F})$, indicating increased sympathetic neurotransmitter release in vivo. Inhibition of sympathetic tone by the $\alpha_{2}$ agonist clonidine led to a greater reduction in SBP in $P d c^{-/-}$than in $P d c^{+/+}$mice (Figure 5G), providing further evidence for enhanced sympathetic tone in $P d c^{-/-}$mice. Similarly, clonidine elicited greater bradycardic responses in $P d c^{-/-}\left(-145 \pm 14 \mathrm{~min}^{-1}, n=8\right)$ than in $P d c^{+/+}$ mice $\left(-70 \pm 34 \mathrm{~min}^{-1}, n=6 ; P<0.05\right)$.

Searching for the mechanism of increased sympathetic activity and circulating norepinephrine, we studied sympathetic function at several levels (Supplemental Figure 1), including brain stem, spinal cord, sympathetic ganglia, and target tissue innervation. In contrast to the peripheral sympathetic system, we did not find evidence for increased norepinephrine content or turnover in the central nervous system, i.e., in whole brain or brain stem, which 
Circadian rhythm
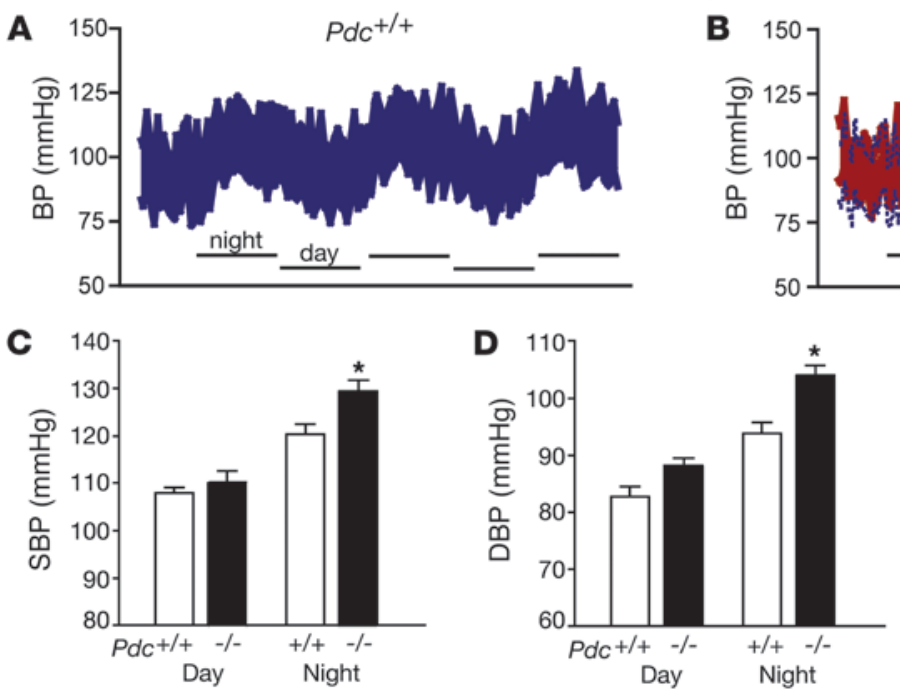

After anesthesia
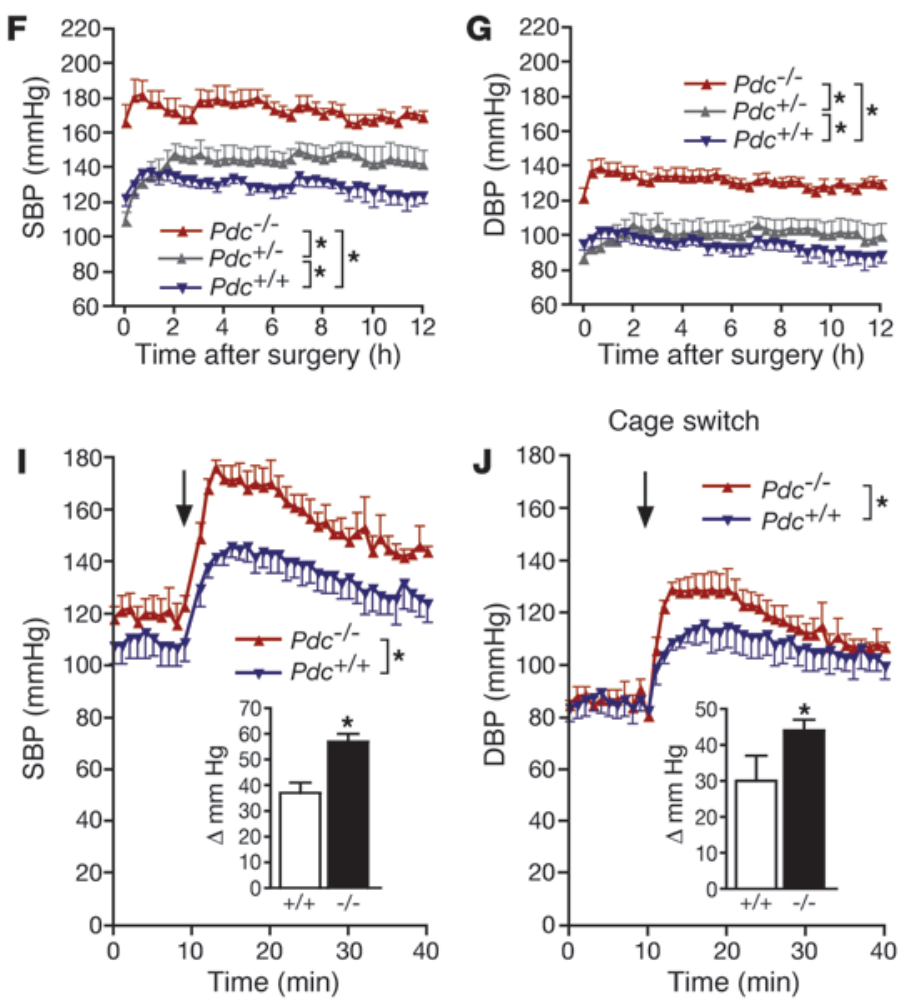

Cage switch

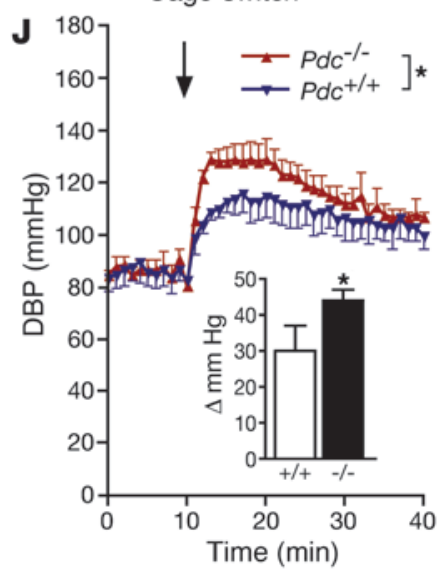

Sympathetic blockade

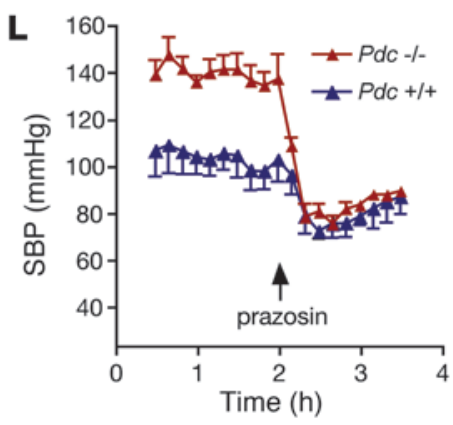

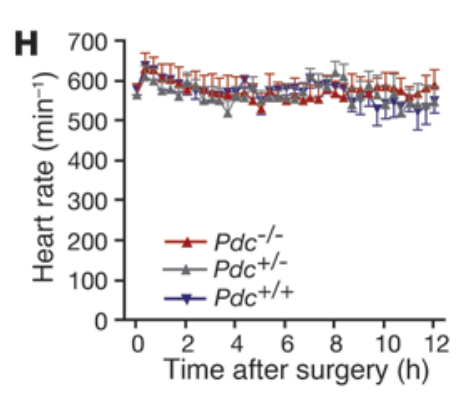
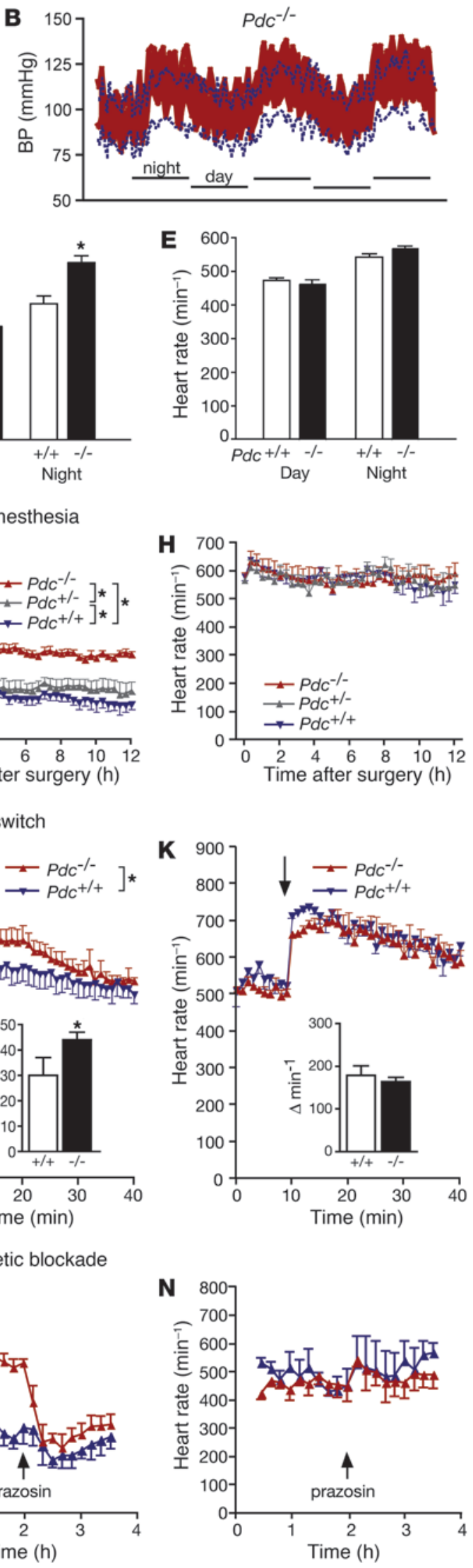

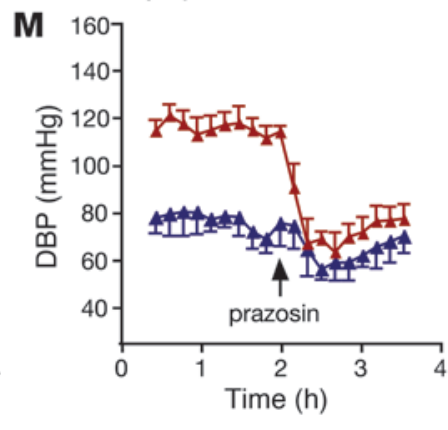

Figure 4

Determination of blood pressure by telemetry. (A and B) Average blood pressure amplitudes (upper limit, SBP; lower limit, DBP) of 6 wild-type (A) and 6 $\mathrm{Pdc}^{-/-}$mice (B; dotted blue lines represent $P d c^{+/+}$pressure values) 2 weeks after implantation of telemetric pressure transducers. (C-E) Mean SBPs and DBPs were elevated at night, but not during day $(n=6$ per genotype; $\left.{ }^{*} P<0.05\right)$. ( $\left.\mathbf{F}-\mathbf{H}\right)$ During the immediate recovery phase from anesthesia after implantation of a telemetric blood pressure transmitter, $\mathrm{Pdc}^{-/}$and $\mathrm{PdC} \mathrm{c}^{+-}$mice were hypertensive ( $n=5-9$ per genotype; $\left.{ }^{*} P<0.05\right)$. (I-K) The hypertensive response after transfer into cages (arrows) that had previously been occupied by different male mice was significantly enhanced in $\mathrm{Pdc}^{-/-} \mathrm{com}$ pared with $\mathrm{PdC}^{+/+}$mice. Insets: Maximal increase in SBP or DBP after cage switch $\left(n=5-6 ;{ }^{*} P<0.05\right)$. (L-N) Blockade of $\alpha_{1}$ adrenoceptors by prazosin ( $2 \mathrm{mg} /$ kg i.p.) normalized elevated blood pressure in $\mathrm{Pdc}^{-/}$mice ( $n=3$ per genotype). 


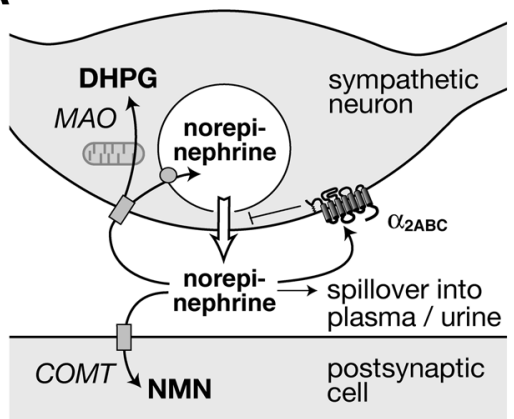

D

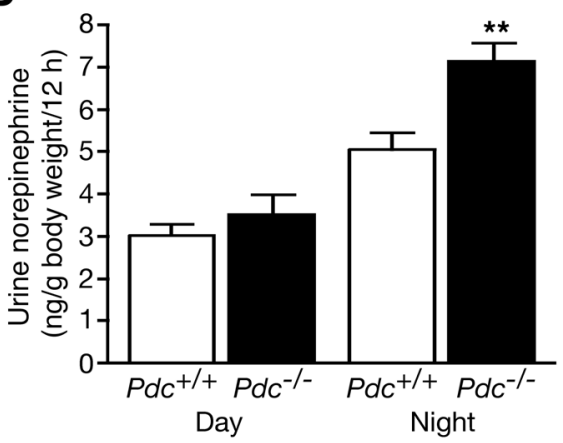

G
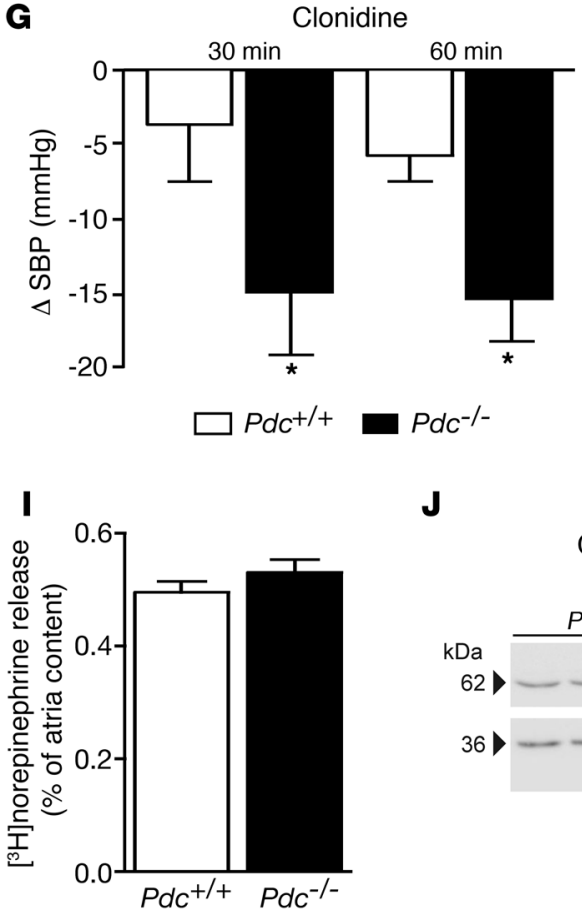

B

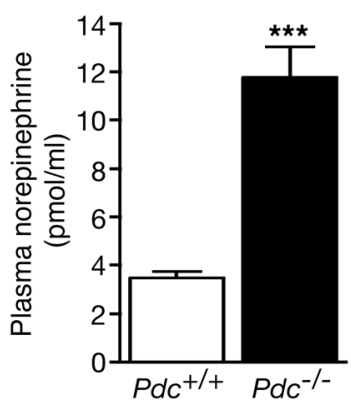

E

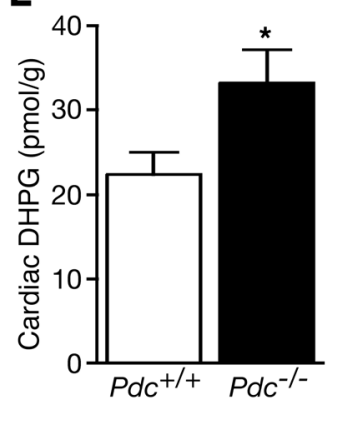

C

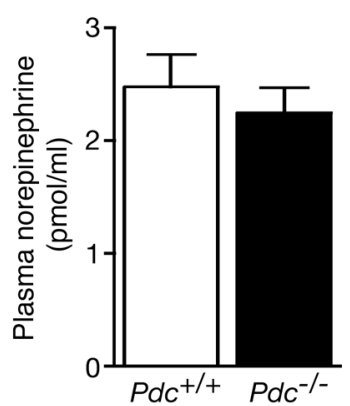

F

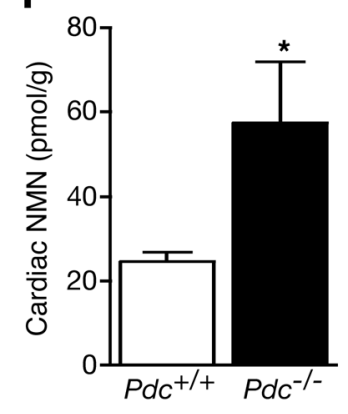

Figure 5

Sympathetic activity is increased in Pdc-deficient mice. (A) Schematic illustration of the fate of norepinephrine after release from sympathetic nerves and its metabolism to DHPG via monoaminoxidase (MAO) or to NMN via catechol-O-methyltransferase (COMT). $\alpha_{2 A B C}, \alpha_{2}$ adrenoceptor subtypes $A, B$, and $\mathbf{C}$. (B and $\mathbf{C}$ ) Circulating plasma norepinephrine levels were elevated in $\mathrm{Pdc}^{-/-}$mice, but epinephrine concentrations were not altered $(n=6-9$; $\left.{ }^{* \star \star} P<0.001\right)$. (D) Renal elimination of norepinephrine was increased in $\mathrm{Pdc}^{-/-}$mice at night $\left(n=18-26\right.$; $\left.{ }^{* \star} P<0.01\right)$. (E and $\mathbf{F})$ Norepinephrine metabolites DHPG and NMN were increased in cardiac tissue of $\mathrm{Pdc}^{-/-}$compared with $\mathrm{PdC}^{+/+}$ animals $\left(n=6-7\right.$; $\left.{ }^{*} P<0.05\right)$. (G) Decrease of SBP after i.p. injection of $30 \mu \mathrm{g} / \mathrm{kg}$ clonidine in $\mathrm{Pdc}^{-/-}$and $\mathrm{Pdc}^{+/+}$animals $\left(n=6-8\right.$; $\left.{ }^{*} P<0.05\right)$. (H) Inhibition of $\left[{ }^{3} \mathrm{H}\right]$ norepinephrine release by the $\alpha_{2}$ adrenoceptor agonist medetomidine did not differ between genotypes ( $n=5-6$ atria per genotype). (I) Electrically evoked release of $\left[{ }^{3} \mathrm{H}\right]$ norepinephrine from isolated cardiac right atria after stimulation with 20 pulses at $50 \mathrm{~Hz}$ ( $n=5-6$ atria). ( $\mathbf{J}$ and $\mathbf{K}$ ) Western blots to determine tyrosine hydroxylase $(\mathrm{TH})$ expression in cardiac ventricles of $\mathrm{Pdc}^{+/+}$and $\mathrm{Pdc}^{-/-}$mice. Tyrosine hydroxylase expression was normalized to $G$ protein $\beta$ levels $\left(G_{\beta}\right)$ ( $n=4-5$ hearts).
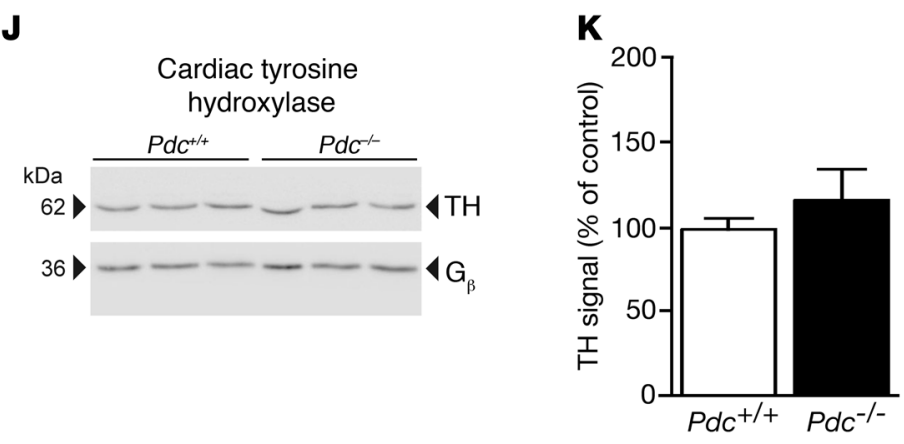

is rich in catecholaminergic neurons regulating hemodynamics (Supplemental Table 2). To study whether preganglionic sympathetic neurons of the intermediolateral column of the thoracic spinal cord were differentially activated between $P d c^{-/-}$and $P d c^{+/+}$ mice during stress-induced hypertension (Figure 4, F and G), immunostaining for $\mathrm{cFos}$ (16) was performed in mice 2-3 hours after surgery (Supplemental Figure 2). Preganglionic sympathetic neurons in the intermediolateral column of the spinal cord were identified by choline acetyltransferase expression (17). The percentage of cFos-positive preganglionic neurons in the intermediolateral cell column did not differ between genotypes (Supplemental Figure $2, P d c^{+/+} 25.0 \% \pm 3.6 \%$ vs. $P d c^{-/-} 26.3 \% \pm 3.0 \%, n=6$ per genotype; $P=0.78$ ).

In order to elucidate whether sympathetic overactivity in $\mathrm{Pdc}^{-/-}$ mice occurred distal to the spinal cord on ganglionic or postganglionic levels, we first investigated hemodynamic responses to direct 
A

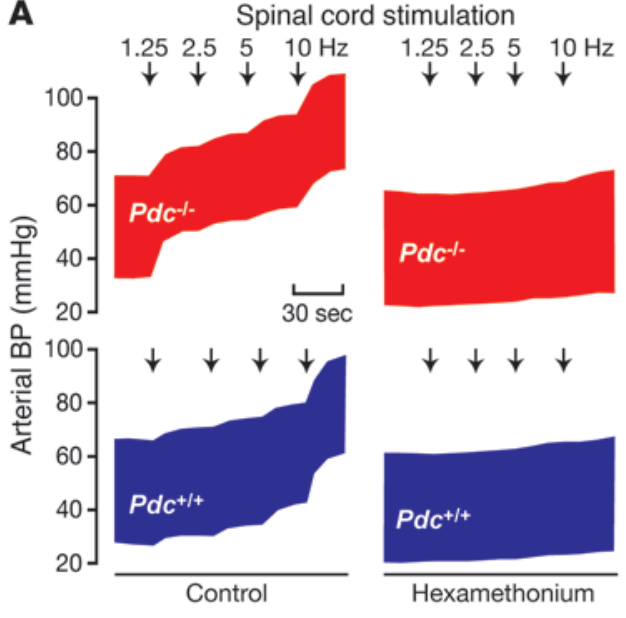

C
B

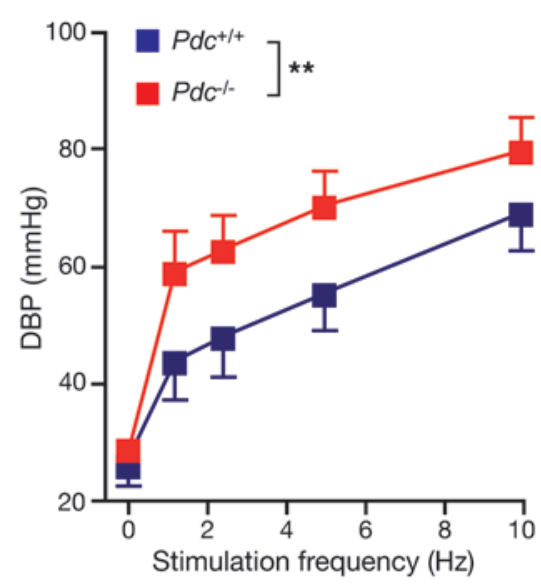

D

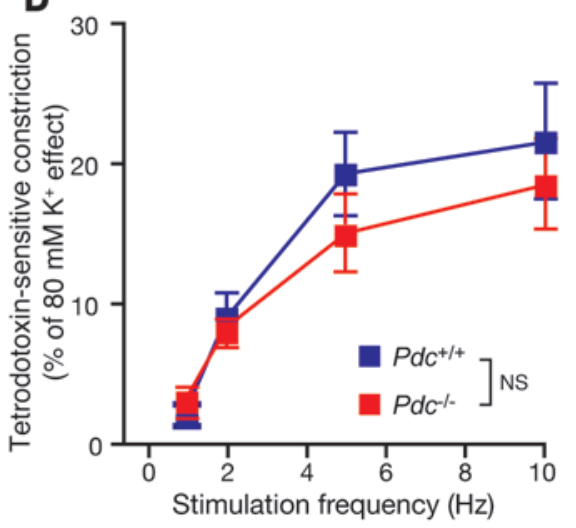

\section{Figure 6}

Effect of electric sympathetic stimulation on in vivo blood pressure and in vitro vasoconstriction. (A and $\mathbf{B}$ ) Spinal nerve stimulation $(1.25-10 \mathrm{~Hz})$ in anesthetized, ventilated mice induced increases in blood pressure that were completely prevented by the ganglionic blocker hexamethonium. (B) Electrical stimulation elicited greater increases in DBP in $\mathrm{Pdc}^{-/-}$than in $\mathrm{PdC}^{+/+}$mice $(n=7-9$ per genotype; ${ }^{\star \star} P<0.01$ ). (C and D) Vasoconstrictory responses of isolated femoral artery first order branches to electrical field stimulation $(1-10 \mathrm{~Hz}$, width $0.05 \mathrm{~ms}$, train length $10 \mathrm{~s}$, amplitude $30 \mathrm{~V}$ ). Tetrodotoxin-sensitive contraction, normalized to $80 \mathrm{mM}$ potassium contraction, was unaltered in $\mathrm{Pdc}^{-/-}$vessels compared with wild-type arteries ( $n=6$ vessels per genotype; $P>0.05$ ).

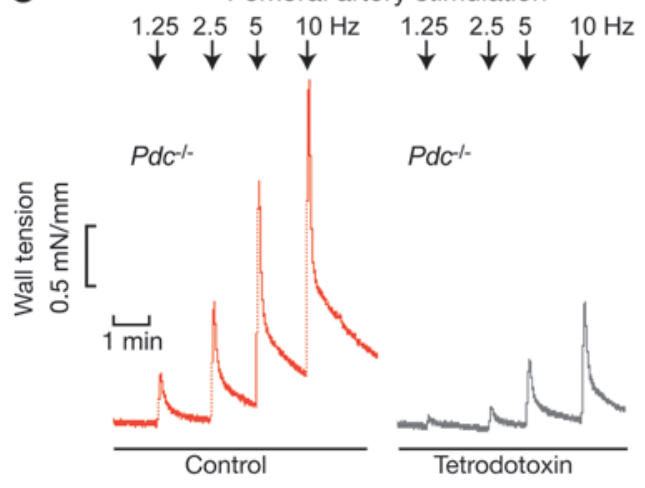

electrical stimulation of the spinal cord during deep anesthesia (Figure 6). Electrical stimulation of preganglionic neurons in the thoracic spinal cord at defined frequencies should reveal whether sympathetic ganglia or distal nerves respond with higher activity to identical input from preganglionic neurons. As expected, spinal cord stimulation resulted in a frequency-dependent increase in SBP and DBP in both genotypes (Figure 6, A and B). Blockade of nicotinic acetylcholine receptors by hexamethonium largely prevented this blood pressure response, proving that indeed sympathetic vasoconstrictory nerves were activated by electrical stimulation of preganglionic neurons in the thoracic spinal cord (Figure $6 \mathrm{~A})$. Interestingly, the rise in blood pressure achieved by stimulation at frequencies between $1.25 \mathrm{~Hz}$ and $10 \mathrm{~Hz}$ was significantly higher in $\mathrm{Pdc}^{-/-}$than in $P d c^{+/+}$mice (Figure 6B). Similarly, the rise in heart rate elicited by spinal cord stimulation was greater in $\mathrm{Pdc}^{-/-}$ $\left(+79.9 \pm 22.0 \mathrm{~min}^{-1}, n=9\right)$ than in $P d c^{+/+}$mice $\left(+19.5 \pm 9.3 \mathrm{~min}^{-1}\right.$, $n=7 ; P<0.05)$, consistent with an amplification of the neuronal signal in sympathetic ganglia or distal nerves.

In order to test whether this amplification occurred at the level of the sympathetic nerves innervating target tissues including vasculature and heart, we next investigated vasoconstrictory responses and norepinephrine release in target tissues during electrical field stimulation in vitro. Isolated first order branches of the femoral artery responded with strong increases in wall tension to electrical stimulation of intramural sympathetic nerves (Figure 6C). Blockade of neuronal voltage-gated $\mathrm{Na}^{+}$channels with tetrodotoxin $(0.5$ $\mu \mathrm{M}$ ) was used to identify the part of the vasoconstrictory response attributable to neurotransmitter release from intramural nerve endings. However, no differences in electrically evoked contraction were detected between $\mathrm{Pdc}^{-/-}$and $\mathrm{Pdc^{+/+ }}$ arteries (Figure 6D).

In order to directly assess feedback control of neurotransmitter release, we measured the secretion of $\left[{ }^{3} \mathrm{H}\right]$ norepinephrine from isolated cardiac atria (Figure 5, H and I). In tissues from both genotypes, electrically stimulated transmitter release was identical (Figure 5I) and could be inhibited by the $\alpha_{2}$ adrenoceptor agonist medetomidine with similar potency and efficacy (Figure $5 \mathrm{H}$ ), demonstrating intact feedback control and neurotransmitter release from sympathetic nerves. Furthermore, expression of tyrosine hydroxylase, the rate-limiting enzyme in catecholamine biosynthesis, in sympathetically innervated tissues, including the heart, was not altered in $\mathrm{Pdc}^{-/-}$mice (Figure 5, J and $\mathrm{K}$ ). Taken together, these data led to the hypothesis that activity or responsiveness of ganglionic sympathetic neurons might be elevated in $\mathrm{Pdc}^{-1-}$ mice.

Thus, we searched for alterations in sympathetic neurons isolated from superior cervical ganglia (SCG) or stellate ganglia, which express Pdc (Figure 7). Neither type of sympathetic ganglia showed genotype-dependent differences in sympathetic neuron number or morphology (Figure 7, A and B). Acetylcholine-induced action potentials persisted significantly longer in sympathetic neurons isolated from $P d c^{-/-}$SCG when compared with wild-type neurons (Figure 7, C and D). Similarly, $P d c^{-/-}$neurons depolarized by current injection displayed higher firing frequencies than did control neurons from $\mathrm{Pdc} \mathrm{c}^{+/+}$mice (Figure 7E). Hyperpolarization-activated $\left(\mathrm{I}_{\mathrm{h}}\right)$ currents and $\mathrm{Na}^{+}$currents were similar in wild-type and $\mathrm{Pdc^{-/ }}$ 

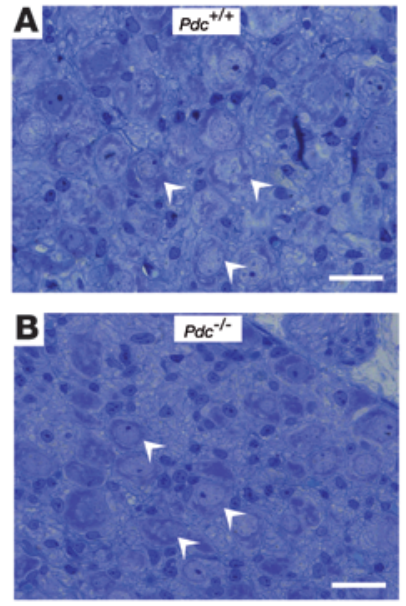

$\mathbf{E}$

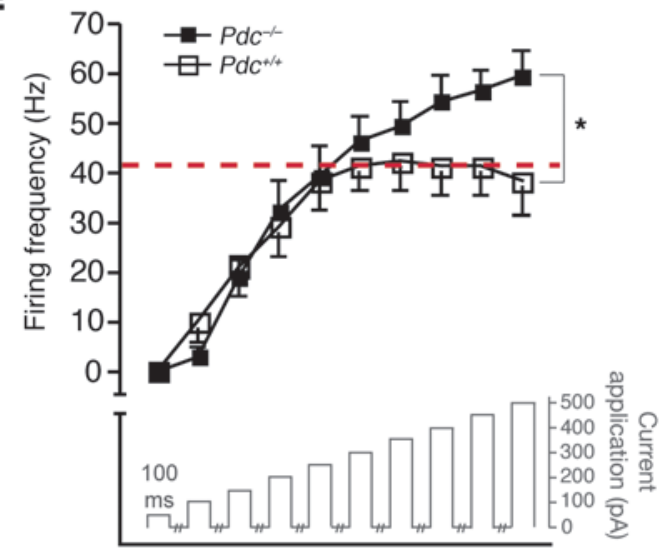

G

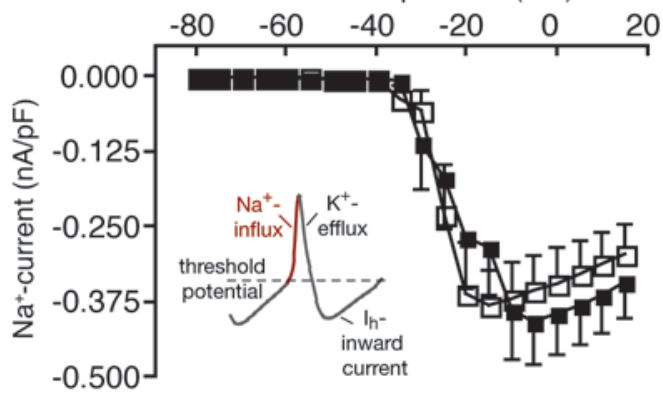

D
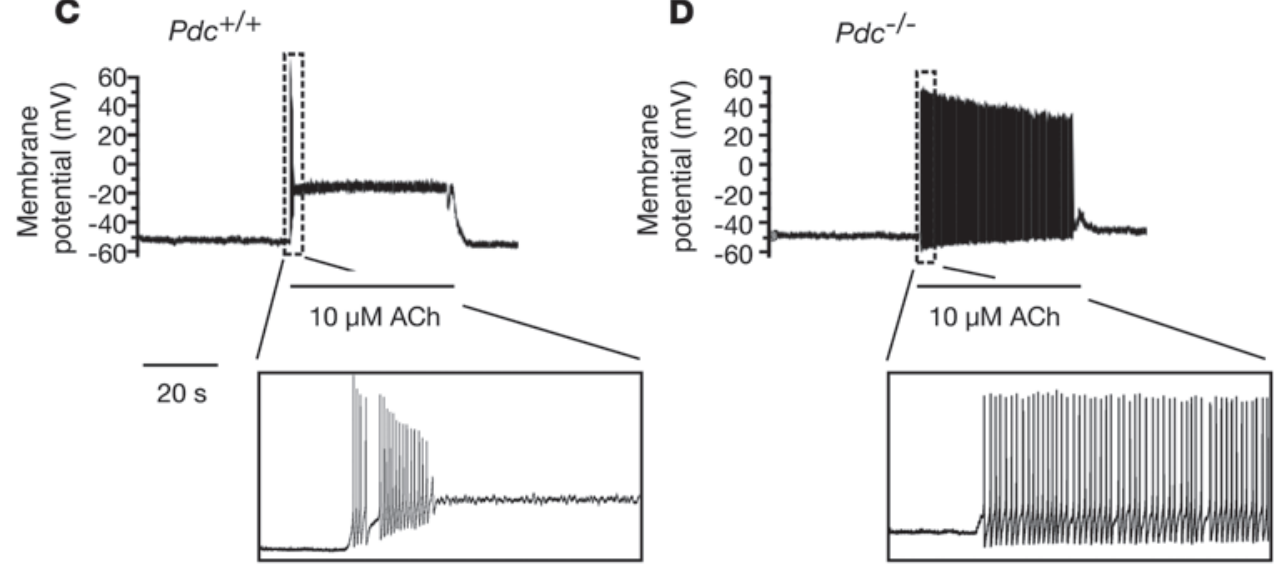

$\mathbf{F}$

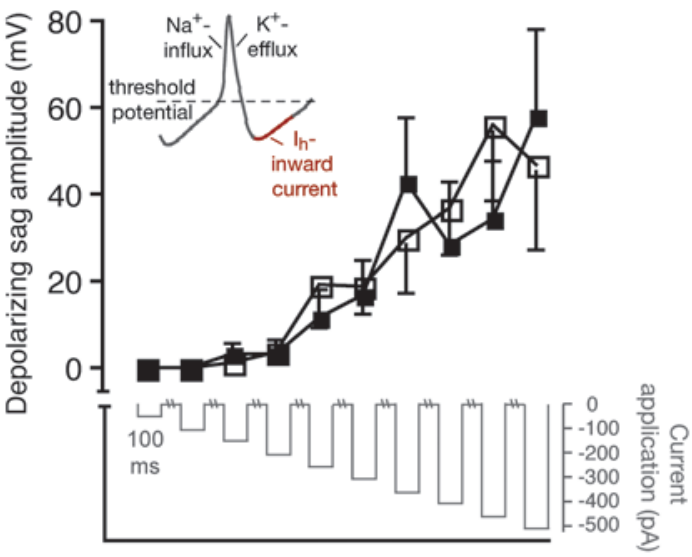

$\mathbf{H}$

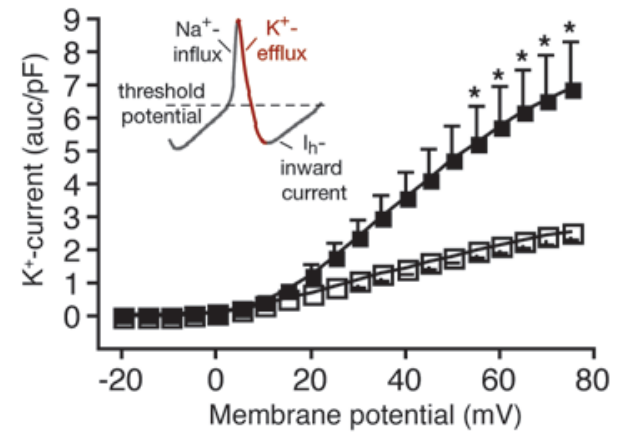

Figure 7

Action potential firing in sympathetic neurons isolated from Pdc-deficient mice. (A and B) Histology of SCG of Pdc $c^{-/-}$and wild-type mice. Arrows indicate perikarya of postganglionic sympathetic neurons (scale bars: $20 \mu \mathrm{m})$. (C and $\mathbf{D})$ Response of sympathetic neurons from $P d c^{+/+}(\mathbf{C})$ and $\mathrm{Pdc}^{-I_{-}}$(D) mice to acetylcholine. Application of $10 \mu \mathrm{M}$ acetylcholine (ACh, indicated by thin bar) depolarized the membrane potential and induced a short train of action potentials (the inset shows the burst at a higher time resolution). Ten of 12 tested cells responded similar to the cell shown (bursting time $<5$ seconds in the presence of $10 \mu \mathrm{M}$ acetylcholine). Sympathetic neurons from Pdc ${ }^{-/-}$mice produced extended trains of action potentials in the presence of $10 \mu \mathrm{M}$ acetylcholine. Seven of 8 cells revealed bursting times between 10 and 40 seconds. (E) Action potential firing after membrane depolarization by current injection in isolated neurons from SCG. Neurons from Pdc $\mathrm{c}^{-/-}$animals displayed a significantly higher firing frequency than wild-type neurons $\left(n=8\right.$ per genotype; $\left.{ }^{*} P<0.05\right)$. ( $\left.\mathbf{F}-\mathbf{H}\right)$ Currents constituting the action potentials were examined. (F) $\mathrm{I}_{\mathrm{h}}$ currents $(\mathrm{HCN})$ did not differ between $\mathrm{Pdc}^{-/-}$and wild-type neurons ( $n=8$ per genotype). (G) Peak $\mathrm{Na}^{+}$currents evoked by membrane depolarization did not differ between genotypes $\left(P d c^{+/+} n=8, P d c^{-/-} n=9\right)$. (H) Depolarization evoked $\mathrm{K}^{+}$currents in the presence of $\mathrm{Na}^{+}$and $\mathrm{Ca}^{2+}$ channel blockers. With increasing membrane depolarization, $\mathrm{K}^{+}$currents in neurons from $\mathrm{Pdc}^{-/}$mice were significantly larger than currents in $P d c^{+/+}$neurons $\left(P d c^{+/+} n=5, P d c^{-/-} n=8 ;{ }^{*} P<0.05\right)$. 
Table 1

Overview of patient data

\begin{tabular}{lcccc} 
Characteristic & \multicolumn{2}{c}{ FC } & \multicolumn{2}{c}{ AA } \\
& Male $(\boldsymbol{n}=\mathbf{3 7 0})$ & Female $(\boldsymbol{n}=\mathbf{4 4 0})$ & Male $(\boldsymbol{n}=\mathbf{1 2 2})$ & Female $(\boldsymbol{n}=\mathbf{2 2 0})$ \\
Age $(\mathrm{yr})$ & $48.75 \pm 13.16$ & $51.53 \pm 14.61$ & $44.51 \pm 8.56$ & $44.55 \pm 8.65$ \\
Waking SBP $(\mathrm{mmHg})$ & $130.49 \pm 14.17$ & $121.76 \pm 15.63$ & $145.55 \pm 14.34$ & $142.10 \pm 17.84$ \\
Waking DBP $(\mathrm{mmHg})$ & $79.97 \pm 9.97$ & $74.45 \pm 10.10$ & $88.05 \pm 9.25$ & $84.72 \pm 10.24$ \\
Standing SBP $(\mathrm{mmHg})$ & $132.58 \pm 19.25$ & $124.23 \pm 23.02$ & $149.45 \pm 16.31$ & $150.87 \pm 21.95$ \\
Standing DBP $(\mathrm{mmHg})$ & $84.78 \pm 12.01$ & $78.40 \pm 10.84$ & $97.90 \pm 12.57$ & $94.94 \pm 13.66$ \\
Post-math SBP $(\mathrm{mmHg})$ & $126.39 \pm 16.60$ & $118.23 \pm 20.41$ & $144.40 \pm 18.79$ & $147.54 \pm 19.62$ \\
Post-math DBP $(\mathrm{mmHg})$ & $80.82 \pm 11.94$ & $71.45 \pm 11.05$ & $93.75 \pm 10.33$ & $89.62 \pm 11.42$ \\
BMl & $27.29 \pm 4.53$ & $26.40 \pm 5.45$ & $29.56 \pm 6.40$ & $33.61 \pm 7.71$ \\
Plasma creatinine $(\mathrm{mg} / \mathrm{dl})$ & $0.98 \pm 0.24$ & $0.77 \pm 0.17$ & $0.99 \pm 0.16$ & $0.80 \pm 0.13$ \\
\hline
\end{tabular}

Values are mean $\pm \mathrm{SD}$.

neurons (Figure 7, F and G). However, $\mathrm{K}^{+}$channel current was significantly greater in $P d c^{-/-}$than in $P d c^{+/+}$neurons (Figure $7 \mathrm{H}$ ), allowing for faster repolarization and thus higher action potential frequencies in $P d c^{-/-}$neurons. These findings establish what we believe is a novel functional link between $P d c$ and stress-induced hypertension due to increased sympathetic activity caused by cellautonomous, increased electrical activity of sympathetic neurons.

In order to further test whether sympathetic activity is generally increased in Pdc-deficient mice, pupil size was measured in mice by infrared confocal scanning laser ophthalmoscopy (Supplemental Figure 3). After overnight dark adaptation, $P d c^{-/}$mice had a significantly larger pupil diameter than $P d c^{+/+}$mice (Supplemental Figure 3, A, D, and G). Increased pupil size was also observed in $P d c^{-1-}$ mice after a brief light flash and after recovery from the flash (Supplemental Figure 3, H and I). Light-induced miosis did not differ between genotypes (decrease in pupil size, $P d c^{-/-}-18.4 \% \pm 1.7 \%$ vs. $P d c^{+/+}-17.8 \% \pm 2.6 \%$ of corneal diameter, $n=8$ per genotype; $P=0.85)$. Mydriasis of the pupil is consistent with increased sympathetic activity in neurons originating in SCG in Pdc-deficient mice.

Cardiovascular end-organ damage in Pdc-deficient mice. Blood pressure dysregulation in $\mathrm{Pdc}^{-/}$mice led to functional and structural changes in the vasculature in older animals ( $>4$ months), which resembled findings in experimental and human essential hypertension (Supplemental Figure 4). In isolated arteries, smooth muscle cells displayed significant hypertrophy (mean myocyte cross-sectional area, $P d c^{-/-} 50.0 \pm 1.6 \mu \mathrm{m}^{2}$ vs. $P d c^{+/+} 33.2 \pm 2.1 \mu \mathrm{m}^{2}$; $P<0.0001$; Supplemental Figure 4, A-C). In addition, vasoconstrictor responses to phenylephrine (Supplemental Figure 4D), angiotensin II, and $\mathrm{K}^{+}$depolarization (data not shown) were increased in iliac arteries from 4-month-old $P d c^{-1-}$ mice compared with wild-type littermates. Furthermore, endothelial dysfunction became apparent in $\mathrm{Pdc}^{-/-}$vessels. Medetomidine-mediated relaxation via activation of endothelial $\alpha_{2}$ adrenoceptors was significantly reduced in $P d c^{-/-}$iliac arteries compared with $P d c^{+/+}$vessels (Supplemental Figure 4E). However, vasorelaxation elicited by the direct guanylyl cyclase activator, sodium nitroprusside, resulted in similar effects in $\mathrm{Pdc}^{-/-}$and in wild-type vessels (Supplemental Figure $4 \mathrm{~F}$ ). As a result of sustained sympathetic overactivity, $\alpha_{1 \mathrm{~b}}$ adrenergic receptor (Adra1b), $\beta_{1}$ adrenergic receptor (Adrb1), and $\beta_{2}$ adrenergic receptor (Adrb2) mRNA was downregulated in aortae of $P d c^{-/-}$compared with $P d c^{+/+}$animals (Supplemental Figure 4G). Pathological alterations were also seen in the heart. Ventricles of $P d c^{-/}$mice aged 4-6 months displayed significant hypertrophy when compared with wild-type values $\left(P d c^{-/-} 7.7 \pm 0.2 \mathrm{mg} / \mathrm{mm}\right.$ vs. $P d c^{+/+} 6.9 \pm 0.2 \mathrm{mg} / \mathrm{mm}$; $P<0.05$; Supplemental Figure $4 \mathrm{H})$. Expression analysis of markers of the fetal gene program, which becomes activated during cardiac hypertrophy, identified a significant upregulation of the $\beta$ isoform of myosin heavy chain (Supplemental Figure 4I).

Association of the buman PDC gene with hypertension. In order to test whether $P D C$ also influences blood pressure phenotypes in humans, we used a family-based association study approach in AA and FC families recruited and phenotyped using the same standardized protocols (Table 1). We fully resequenced the PDC gene in $48 \mathrm{AA}$ and $48 \mathrm{FC}$ unrelated individuals to select SNPs that define the haplotype structure in detail. Through sequencing, we identified what we believe are novel SNPs and verified a total of 49 SNPs. Of those SNPs, 3 were in the PDC untranslated region of the transcript. The remaining SNPs were located at $5^{\prime}, 3^{\prime}$, and intronic regions (Supplemental Table 3 and Figure 8, A and B). In addition, we selected SNPs from public databases for prostaglandin-endoperoxide synthase 2 (PTGS2, also known as cyclooxygenase-2 [COX2] or prostaglandin $\mathrm{G} / \mathrm{H}$ synthase), as this gene is in close proximity to PDC. Singlepoint and haplotype-based association analysis was performed, and pairwise linkage disequilibrium (LD) was calculated for genotyped markers $(18,19)$ (Figure 8A).

Significant associations for blood pressure phenotypes were found in both populations at markers in $P D C$, and the neighboring region extending into the PTGS2 gene (Figure 8A). High levels of LD in the FC population covered the entire $222-\mathrm{kb}$ region, but $\mathrm{LD}$ was broken down between the 2 genes in the AA population (Figure $8 \mathrm{~A}$ ).

In the FC families, we detected significant association for multiple SNPs in PDC for average wake SBP and DBP (Figure 8). The most significant association signals $(P<0.0005)$ were detected for wake DBP for markers in the PDC gene as well as for flanking SNPs. These results were confirmed by 2 - and 3-marker sliding-window haplotype analysis (3-marker haplotype: rs1929095-rs7556360; $P=0.00001)$. In addition, we detected a significant association with SBP 4 minutes after a postural change from supine to standing, SBP 8 minutes after a 2 minute math test, as well as DBP after the math test $(P<0.0005)$.

We used generalized estimating equations to calculate the genotype-specific blood pressure for the rs12402521 SNP (Figure 8, C and $\mathrm{D}$ ). Individuals homozygous for the $\mathrm{G}$ allele had an increased average wake SBP of $15 \mathrm{mmHg}$ for FC and $12 \mathrm{mmHg}$ for AA when compared with those homozygous for the A allele $(P<0.0001$; Figure $8, C$ and D). Heterozygote individuals expressed intermediate blood pressure levels, thereby suggesting a gene-dosage-dependent effect of $P D C$.

As 2 LD blocks separating PDC and PTGS2 were identified in the AA population (Figure 8A), we performed a detailed association analysis of 6 representative phenotypes of resting and stress blood pressure (Table 2). Significant associations were found for PDC SNPs in the AA population predominantly for stress phenotypes, 
A

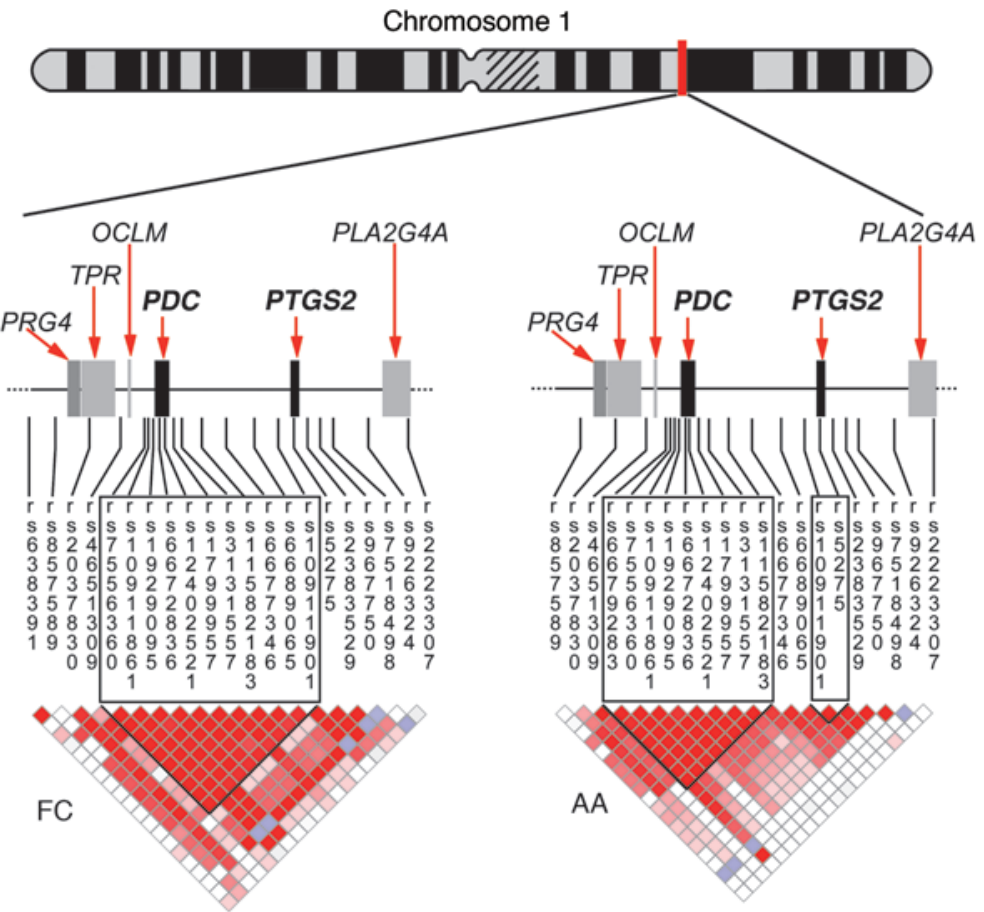

B

Location |184,676,382
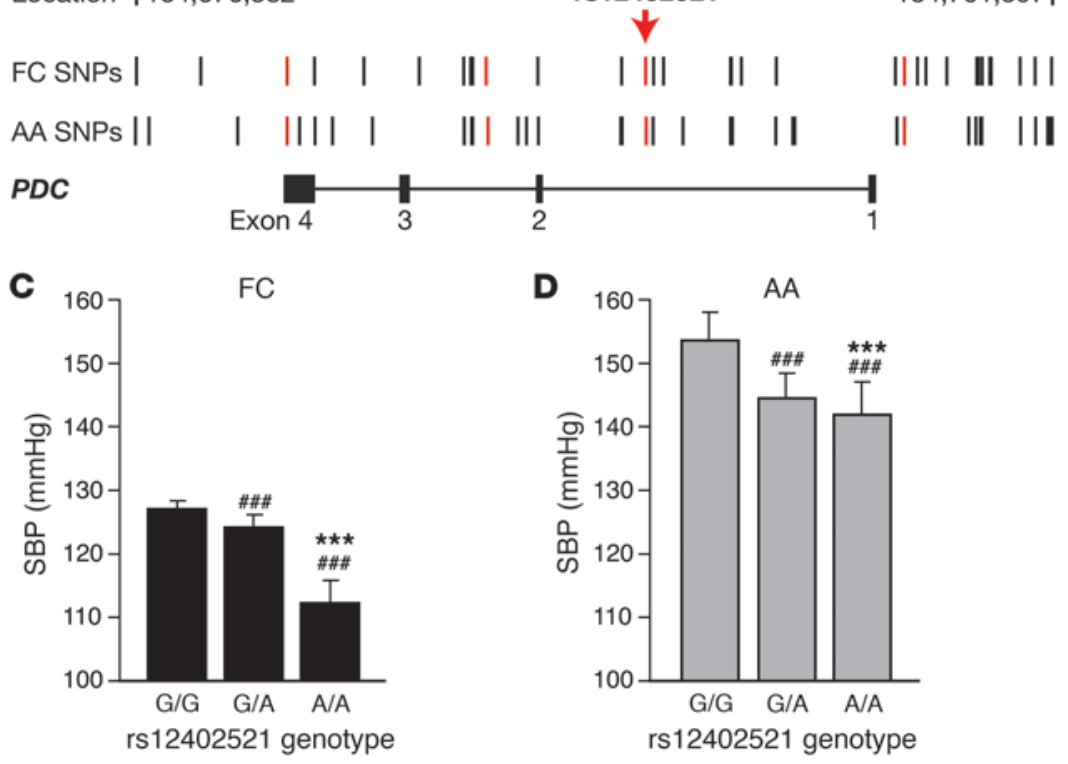

Figure 8

Genetic mapping of blood pressure loci on human chromosome 1. (A) LD structure for the PDC, PTGS2 region on chromosome 1 of $F C$ (left) and $A A$ (right) populations. D' values for LD between each marker (red $=\mathrm{D}^{\prime}>0.8$ ) are presented. In the FC group, $P D C$ and PTGS2 cosegregated in 1 large block of LD, which was separated into 2 LD blocks in the AA population. PRG4, proteoglycan 4; TPR, translocated promoter region; OCLM, oculomedin; PLA2G4A, phospholipase A2 group IV A. (B) SNPs in 2 human populations are shown in their genomic location in relation to the $P D C$ gene. SNPs highlighted in red were genotyped in the full $F C$ and $A A$ populations. (C and D) Average wake SBP in FC and AA populations according to SNP rs12402521 genotype. Generalized estimating equations were used to adjust for familial correlation, age, and gender $\left({ }^{* * *} P<0.0001\right.$ vs. G/A genotype; \#\#\# $P<0.0001$ vs. G/G genotype).

Published data from genome-wide association studies (GWASs) in a Scandinavian population with type 2 diabetes (21) and the WTCCC consortium (22) both show association with $P D C$, thus providing additional independent replications of our findings. The Scandinavian study showed association with SBP with a SNP typed for all 4 populations in PDC (rs12402521; $P=0.0047$ ) as well as other SNPs in the intergenic region, which spans the LD block to PTGS2 (rs10911877, $P=0.007$; rs11584662, $P=0.0019$; rs16825675, $P=0.0094$ ) (ref. 21; blood pressure trait data were accessed via the Broad Institute; http://www.broad.mit.edu/diabetes). The WTCCC study reconfirmed the association of rs12402521 with SBP $(P=0.0079)(22)$. Finally, the combined analysis using Fisher's combined probability test yielded a $P$ value of $5.2 \times 10^{-5}$. Taken together, our data show a replicated, highly significant, and clinically important effect for the hypertension gene PDC in independent and diverse populations.

Hypertension in mice lacking expression of PTGS2. Given the observed association between blood pressure phenotypes and PTGS2 in humans, we complemented the analysis and investigated whether heterozygous or homozygous Ptgs2deficient mice also displayed characteristics of stress-dependent hypertension. Basal blood especially in response to standing and after a math test for both SBP and DBP (Table 2). Haplotype marker analysis confirmed the positive association for stress-related phenotypes, in particular for math DBP (2 marker haplotype: rs6672836-rs1929095; $P=0.0022)$. For $P T G S 2$, we detected significant associations in the AA sibling pairs for wake SBP (Table 2). Furthermore stress blood pressure phenotypes were also significantly associated with PTGS2 SNPs. Adjusted $P$ values using false discovery rate (FDR) analysis to account for multiple testing (20) remained significant in the AA population (Table 2). At the same time, we did not observe an association for heart rate in the FC or AA cohorts. These findings are consistent with the results in the mouse model. pressure as assessed by telemetry was significantly higher in Ptgs2 $2^{-/}$mice than in Ptgs2 $2^{+/-}$or wild-type mice (Figure 9, A and B). However, in contrast to Pdc-deficient mice, Ptgs $2^{-/-}$mice had higher SBP during the inactive day and the active night periods (Figure 9A), and there was no significant difference between genotypes in response to stress (cage switch) (Figure $9, \mathrm{C}$ and D). Deletion of the $P d c$ gene did not affect expression of Ptgs 2 mRNA in kidney, aorta, or lung from $P d c^{-/-}$mice (Ptgs2 mRNA in $P d c^{-/-}$tissues: $92 \% \pm 6 \%, 97 \% \pm 8 \%$, and $70 \% \pm 10 \%$ of $P d c^{+/+}$, respectively). Thus, it is unlikely that the observed stressdependent hypertension in $P d c^{-/-}$mice is mediated through a Ptgs2-dependent pathway. 


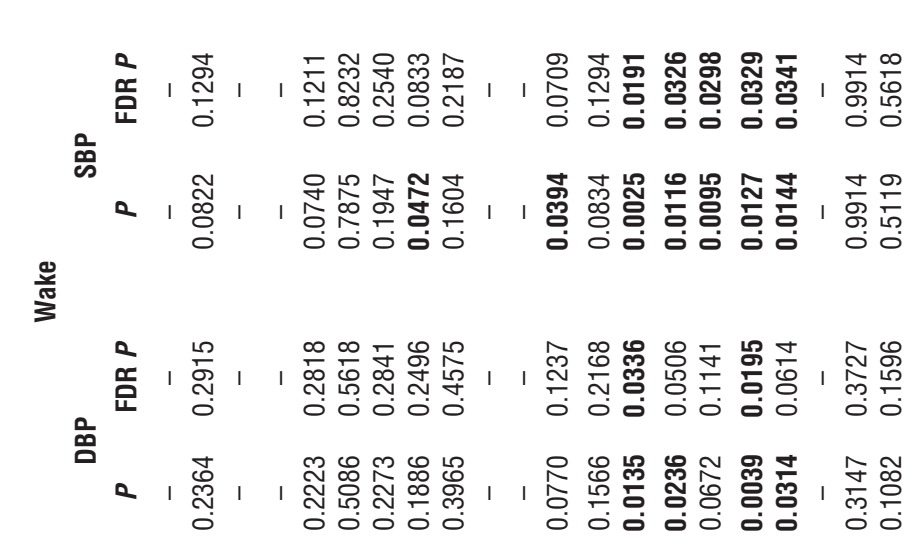

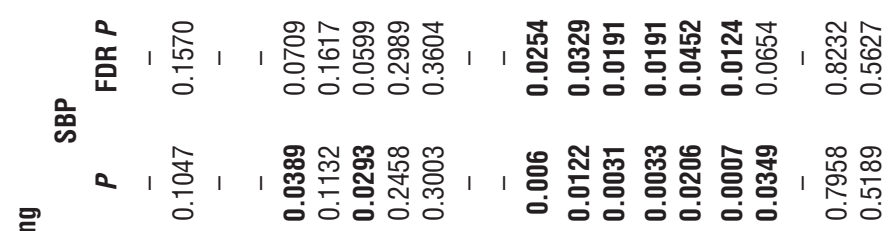

言

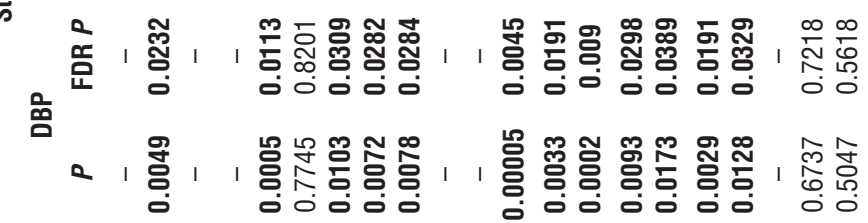

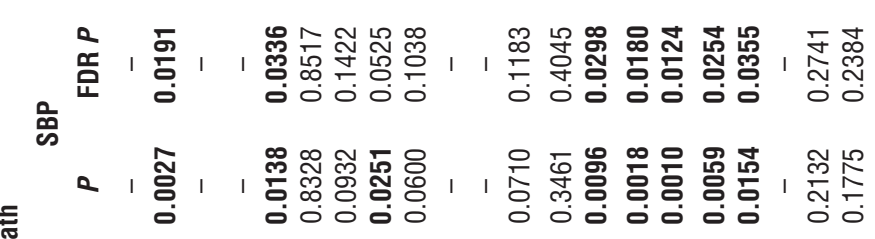

离

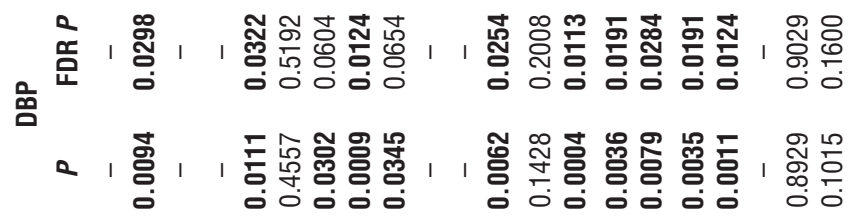

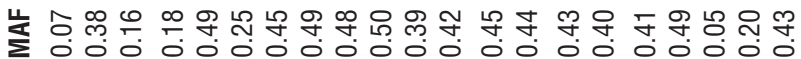

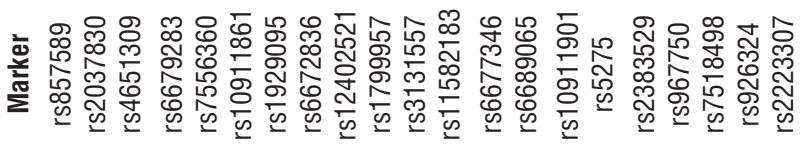

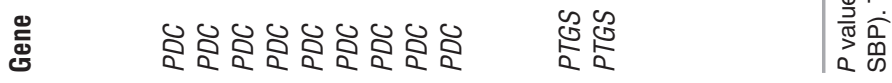

\section{Discussion}

The present study identifies PDC as what we believe is a novel target gene for stress-dependent hypertension in mice and humans. Enhanced activity of postganglionic sympathetic neurons was identified as an underlying cause of hypertension in mice deficient in Pdc. Several lines of evidence suggest that the sympathetic system is responsible for the cardiovascular phenotype.

First, arterial pressure was elevated in parallel with sympathetic activity, i.e., during nighttime, in response to transfer into a novel environment and during post-operative stress. In contrast, cardiac, vascular, and renal morphology and function were not primarily altered in mice lacking Pdc. In vivo and in vitro effects of agonists activating cardiomyocyte $\beta_{1}$ adrenoceptors (dobutamine, norepinephrine) or vascular $\alpha_{1}$ adrenoceptors (norepinephrine, phenylephrine) were normal in $P d c^{-/}$mice. In parallel with increased nighttime blood pressure, plasma and urine catecholamines were significantly elevated in $\mathrm{Pdc}^{-/-}$mice. Moreover, tissue metabolites of norepinephrine (DHPG, NMN), which specifically indicate elevated transmitter release in vivo were elevated in $\mathrm{Pdc}^{-/}$hearts. In addition, in vivo blockade of vascular $\alpha_{1}$ adrenoceptors by the antagonist prazosin or inhibition of enhanced sympathetic tone by the $\alpha_{2}$ adrenoceptor agonist clonidine normalized elevated blood pressure in $P d c^{-/-}$mice to the same levels as in $\mathrm{Pdc}^{+/+}$animals, indicating that elevated sympathetic activity of vasoconstrictory nerves was the prime cause of Pdc-dependent hypertension.

These results are consistent with the expression of Pdc in postganglionic sympathetic ganglia (Figure 1). Sympathetic ganglia from $\mathrm{Pdc}^{-1-}$ mice were normal in several aspects including morphology, presynaptic feedback inhibition of norepinephrine release, and innervation density of peripheral organs as assessed by tyrosine hydroxylase expression in the heart. However, neurons isolated from sympathetic ganglia displayed elevated action potential firing in response to stimulation by acetylcholine or electrical depolarization. This phenotype was cell autonomous, i.e., persisted during the 1- to 3-day period of in vitro culture of these cells. We identified enhanced $\mathrm{K}^{+}$current density in $\mathrm{Pdc}^{-/-}$neurons, which may allow for faster repolarization and electrical activity. Future studies will be important to identify the precise molecular mechanism(s) causing enhanced electrical activity in Pdcdeficient sympathetic neurons. 

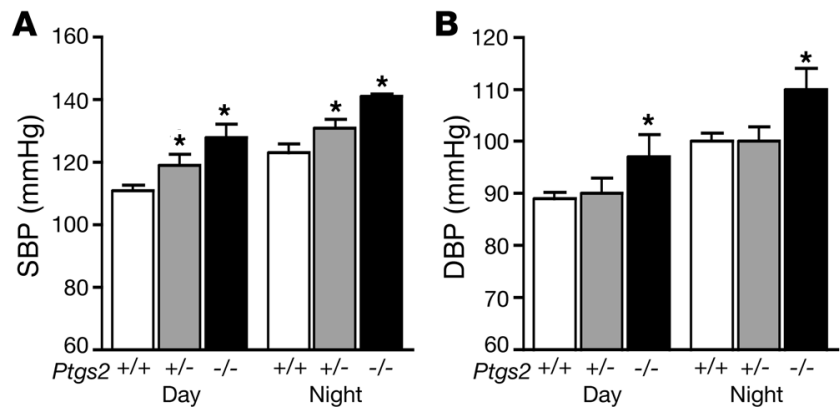

\section{Figure 9}

Blood pressure of mice deficient in Ptgs2. (A-D) Resting SBP (A) and DBP (B) and stress-induced SBP (C) and DBP (D) were determined in wild-type $\left(\right.$ Ptgs $\left.^{+/+}\right)$, heterozygous $\left(P \operatorname{tgs} 2^{+/-}\right)$, and homozygous $\left(\right.$ Ptgs $\left.^{-1-}\right)$ mice after implantation of a telemetric pressure transmitter. (A and B) Deletion of the Ptgs2 gene led to increased SBP and DBP during day and night $\left(n=4-6\right.$; $\left.{ }^{*} P<0.05\right)$. (C and D) Despite different resting blood pressures, the hypertensive response upon transfer of mice into a novel cage environment did not differ between genotypes. Insets: Maximal increase in SBP (left) and DBP (right) pressure after cage switch ( $n=6-8$ per genotype).
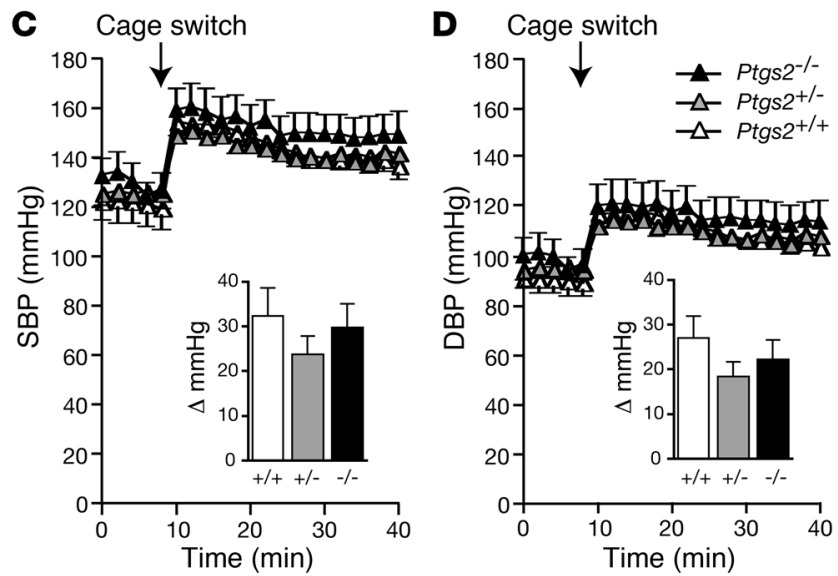

population were linked with elevated SBP at rest, 5 SNPs in the linkage block containing $P D C$ were associated with an increased blood pressure response to a change from sitting to standing or after a math test (Table 2).

Individuals homozygous for the G allele of a PDC SNP (rs12402521) had blood pressure levels 12-15 mmHg higher than humans homozygous for the A allele. Notably, a $10-\mathrm{mmHg}$ increase in SBP has been shown to be associated with a doubling of the risk of end-stage renal disease in persons with diabetes (26), a $40 \%$ increased risk of stroke death, and a $30 \%$ increased risk of ischemic heart disease (27).

In the AA population, 2 adjacent linkage blocks on chromosome 1 were identified, one centered around $P D C$ and the other containing PTGS2. In contrast to PDC, SNPs in the PTGS2 gene were linked with both, resting and stress blood pressure phenotypes. Clinical studies have shown that patients receiving PTGS2-selective inhibitors have an increased risk of thromboembolic events, including stroke and myocardial infarction, as well as a small but significant increase in blood pressure $(28,29)$. Ptgs2-deficient mice showed marked renal pathology starting early after birth as well as strain- and sex-dependent elevations in blood pressure (30-32). Our studies demonstrated that mice deficient in Ptgs2 were hypertensive but did not show increased blood pressure after cage switching. Furthermore, expression of Ptgs2 mRNA was not altered in mice lacking Pdc, indicating that the phenotypes of mice lacking Pdc or Ptgs2 developed by separate molecular mechanisms.

Our genetic data are supported by a number of independent observations linking PDC SNPs with increased blood pressure. First, in 2 populations of AA or FC origin, a linkage block containing the $P D C$ gene was associated with high blood pressure phenotypes (Figure 8). Recently published data from GWASs in a Scandinavian population with type 2 diabetes and the WTCCC consortium both showed association to $P D C$, thus providing additional independent replications. Therefore, our data show a consistent, highly significant, and clinically important effect for the hypertension gene PDC in 4 large independent and diverse populations, namely FCs, AAs, Scandinavians (21), and British Caucasians (22). Combining the evidence for association from all cohorts yielded a highly significant $P$ value of $5.2 \times 10^{-5}$. This replication and strong association in multiple cohorts of various ethnic backgrounds gives strong support for a significant role of SNPs in the PDC gene in humans. To our knowledge, this is the first study that combines evidence of association from various ethnic cohorts and a replication from 2 independent large GWASs. It is likely that the most promising approach to expand results from GWASs will be the combination of association analysis in other cohorts as well as a functional evaluation in model organ systems 
as it becomes increasingly clear that association results require further functional validation. So far, the results of GWASs have resulted in only a few genes and SNPs at the required significance level. Nevertheless, given the polygenic nature of complex diseases, it is fair to assume that a number of SNPs in these GWASs that do not reach the predetermined cut off for genome-wide significance are localized in genes exerting significant effects on a phenotypic level. Consequently, combined statistical evidence from association analyses and functional evidence in animal models as presented here demonstrate the power of comparative genetics. To our knowledge, our report is the first to expand on the results of multiple studies by combining various lines of evidence in support of a functional candidate for hypertension and therefore might serve as an example of future studies for other candidate genes in complex diseases. In the context of genes identified and linked to hypertension, $P D C$ stands out, as to our knowledge this is the first report linking this gene to hypertension in humans and animals. So far most attention has been given to the analysis of functional candidate genes such as members of the renin-angiotensin system (33). However, we expanded this approach by the comprehensive dissection of the functional mechanisms of $P D C$ in the mouse model. Given the tremendous wealth of GWASs, we anticipate that not only for hypertension but many other diseases, this approach will characterize more clearly the functional link to the phenotype of interest. While the animal model directs to a complex function of $P D C$ and a link to sympathetic activity, the association in 4 independent human cohorts describes the impact of variation in $P D C$ on blood pressure as the ultimately clinical phenotype. Although we evaluated both hypertension as well as blood pressure response under various challenges as intermediate phenotypes, our study does not directly evaluate sympathetic activity in humans. While future studies in humans are clearly warranted to further dissect the effect of these SNPs on direct measurements of sympathetic tone, we feel that the focus on blood pressure itself ultimately shows the clinical relevance and further supports the notion of $P D C$ as a potential attractive therapeutic target. The effect of $P D C$ on blood pressure and the detailed functional dissection of the underlying mechanisms in the animal model suggest $P D C$ as a novel and highly likely therapeutic target. This is particularly relevant, as the treatment options for stress-induced hypertension are currently quite limited (34).

In summary, we describe $P D C$ as a gene that influences blood pressure in humans and mice in response to stress. Pdc-deficient mice showed normal survival, kidney morphology, and stressdependent hypertension. We established a mechanism for the development of hypertension and demonstrate that the underlying functional correlate is an increase in sympathetic electrical activity due to specific changes in $\mathrm{K}^{+}$currents, which results in a consecutive faster repolarization. Pdc is expressed in sympathetic ganglia of the peripheral nervous system network controlling sympathetic tone (5). Our studies emphasize the important role of the adrenergic system in particular for stress-induced and "white coat" hypertension (4). PDC does not affect basal blood pressure at rest but limits the influence of sympathetic activation on blood pressure and thus differs conceptually from the drugs commonly used to treat human hypertension, which affect both resting and hypertensive blood pressure. Thus, PDC represents a high-value drug target, and pharmacological modulation of PDC function may represent a novel mechanism to limit sympathetic activity and to treat stress-induced hypertension.

\section{Methods}

\section{Characterization of gene-targeted mouse models}

Generation of Pdc-deficient mice. For targeted disruption of the murine $P d c$ gene, the second exon containing the translation start site was replaced by a neomycin resistance cassette as described before (35). For negative selection, a herpes simplex virus thymidine kinase ( $h s v$-tk) was used. E14 ES cells were electroporated, and ES cell clones with correctly targeted $P d c$ alleles were detected by Southern blotting using external probes (Figure 1). Two targeted ES cell clones were used for blastocyst injections and resulted in male chimeras that transmitted the Pdc mutation through the germline. The $P d c$ mutation was backcrossed for 11 generations onto a C57BL/ 6 background. The following primers were used for genotyping ( $5^{\prime}$ to $3^{\prime}$ direction): $P d c^{-}$and $P d c^{+}$allele, forward: ATGAGATATTGGGGTAGAGC; $P d c^{-}$allele reverse: TGACTCTAGAACTAGTGGAT; $P d c^{+}$allele reverse: GGGAAAGAGTGTGTTGAAT. Pdc protein expression was detected by Western blotting using a polyclonal antiserum raised against purified bovine PDC (36). Ptgs $2^{-/-}$mice were maintained on a hybrid C57BL/6J × 129/Ola genetic background intercrossed for 15-20 generations (31). Mice were genotyped by PCR using DNA isolated from tail biopsies as previously described (37). All mice were housed under specific pathogen-free conditions. Animals obtained water ad libitum and were fed a breeding diet containing $0.23 \% \mathrm{Na}^{+}$and $0.95 \%$ $\mathrm{K}^{+}$. Animal experiments were approved by the responsible authorities of the University of Würzburg and the University of Freiburg.

RNA isolation and reverse transcription. Total cellular RNA was isolated from frozen tissues using RNeasy kits (Qiagen). Contaminating genomic DNA was removed using DNase I (Qiagen). Total RNA $(5 \mu \mathrm{g})$ was reverse transcribed using $500 \mathrm{ng} / \mu \mathrm{l}$ oligo(dT) primer (Fermentas and Qiagen), $1 \mathrm{mM}$ of each dNTP (Fermentas), $20 \mathrm{U}$ of ribonuclease inhibitor (Fermentas), and $200 \mathrm{U}$ of M-MuLV reverse transcriptase RevertAid (Fermentas) in a total volume of $20 \mu \mathrm{l}$.

Real-time RT-PCR. Real-time RT-PCR was performed using an ABI PRISM $7900 H T$ Sequence Detection System (Applied Biosystems) or an MX3000P detector (Stratagene) and the QuantiTect SYBR Green PCR kit (Qiagen) $(38,39)$. Cycling parameters were as follows: initial denaturation at $95^{\circ} \mathrm{C}$ for 10 minutes, followed by 40 cycles of 15 seconds at $95^{\circ} \mathrm{C}$ and 60 seconds at $60^{\circ} \mathrm{C}$. Each reaction contained cDNA corresponding to $0.2-7 \mathrm{ng}$ total RNA and $200 \mathrm{nM}$ of forward and reverse primer. Expression values were normalized to expression of Actb ( $\beta$-actin), Srp14, Gapdh, or Ppib. The identity of the PCR products was verified by subcloning and sequencing, melting point analysis, and nested PCR amplification $(38,39)$. To determine copy numbers, a dilution series of linearized pDrive-Pdc plasmid was used.

Branched DNA assay. Probe sets for mouse $P d c$ and Gapdh mRNA were obtained from Panomics. Unamplified, gene-specific mRNAs were detected by the Quantigene 2.0 branched DNA signal amplification assay (Panomics). Tissues were collected and transferred to RNALater or RNALater-ICE (Ambion) and homogenized in Quantigene homogenization solution and proteinase K. All subsequent steps were performed according to the manufacturer's protocol. All samples were performed in triplicate with removal of the background signal and normalization to Gapdh expression levels.

Cardiovascular physiology. All cardiovascular studies were performed in male littermate mice. For invasive hemodynamics, 6- to 10-week-old mice were anesthetized by isoflurane $\left(2 \%\right.$ vol in $\left.\mathrm{O}_{2}\right)$ and catheterized via the right carotid artery with a 1.4F Millar microtip catheter (mean body weight: $\mathrm{Pdc}^{-1-}$ $24.7 \pm 0.4 \mathrm{~g}, P d c^{+/+} 22.0 \pm 0.5 \mathrm{~g}$ ) (40). Hemodynamic evaluations by telemetry were performed in Pdc-deficient or Ptgs2-deficient mice and control mice after implantation of pressure transmitters TA11PA-C10 (DSI; Transoma Medical) into the left carotid artery (40). $P d c^{-/-}$and $P d c^{+/+}$mice did not differ in their mean body weight $\left(P d c^{-/-} 29.1 \pm 1.1 \mathrm{~g}, P d c^{+/+} 30.1 \pm 0.2 \mathrm{~g}\right)$. Clonidine-induced hemodynamic effects were measured telemetrically 
after i.p. injection $(30 \mu \mathrm{g} / \mathrm{kg})$. Isolated segments of iliac and femoral arteries were examined in an isometric microvessel myograph (41). For morphometric analysis of arteries, segments of the femoral arteries of $P d c^{-1-}$ and $P d c^{+/+}$mice were removed after pressure-controlled perfusion with $4 \%$ paraformaldehyde. Vessels were embedded in araldite, cut longitudinally on a Leica microtome in slices of $1 \mu \mathrm{m}$, and stained with methylene blue (41). Histology of the SCG was performed using the same method.

Levels of catecholamines and metabolites. Urine was collected from groups of 3-5 male mice per genotype aged 7-9 weeks for 12-14 hours during night or for 10-12 hours during daytime (42). To obtain plasma and heart tissue, mice were anesthetized with isoflurane and blood was collected from the carotid artery in tubes containing 0.5 M EDTA, pH 8.0, and centrifuged. The heart was removed, placed into $0.2 \mathrm{M}$ perchloric acid and deep frozen in liquid nitrogen. The assay of monoamines in urine, plasma, and tissues was performed by HPLC with electrochemical detection (42). In brief, monoamines from aliquots of acidified urine, plasma, or perchloric acid extracts of heart tissue were adsorbed onto alumina together with 3,4-dihydroxybenzylamine hydrobromide as an internal standard. The adsorbed catecholamines were then eluted from the alumina with $0.2 \mathrm{M}$ perchloric acid on Costar Spin-X microfilter tubes, and $50 \mu l$ of the eluate was injected into the HPLC system (Gilson model 141; Gilson Medical Electronics). For determination of NMN, $50 \mu \mathrm{l}$ of the filtered perchloric acid extract of heart tissues was injected directly into the HPLC system (42). Release of $\left[{ }^{3} \mathrm{H}\right]$ norepinephrine from isolated cardiac atria was determined as previously described (43).

Field stimulation of isolated arteries. Vasoconstriction in response to electrical field stimulation was investigated in isolated femoral artery branches mounted in a small vessel myograph (stimulation parameters: $1-10 \mathrm{~Hz}$, width $0.05 \mathrm{~ms}$, train length $10 \mathrm{~s}$, amplitude $30 \mathrm{~V}$ ). Neuronal $\mathrm{Na}^{+}$channels were blocked by $0.5 \mu \mathrm{M}$ tetrodotoxin.

Spinal sympathetic stimulation. The effect of electrical spinal cord stimulation on aortic blood pressure was studied by inserting stimulation electrodes into the thoracic part of the vertebrae channel under isoflurane anesthesia. A reference electrode was fixed externally. After muscle relaxation with $0.02 \mathrm{mmol} / \mathrm{kg}$ gallamin, mice were intubated via a tracheal incision and ventilated with a stroke volume of $125 \mu \mathrm{l}$ with $2 \%$ isoflurane/oxygen at a frequency of 30 strokes/minute. A 1.4F millar catheter was inserted into the right carotid artery to allow for measurement of hemodynamic changes. Ganglionic blockade was achieved by administration of $50 \mathrm{mg} / \mathrm{kg}$ hexamethonium i.p. Stimulation parameters were as follows: amplitude $3 \mathrm{~V}, 1 \mathrm{~ms}$ duration, frequency $1.25-10 \mathrm{~Hz}$, train duration 30 seconds.

Pupil measurements. Mice were dark-adapted overnight and placed in front of a confocal scanning laser ophthalmoscope (HRA I; Heidelberg Engineering) under dim red light conditions. Pupil reactions of the left eye were recorded continuously over a 30 -second period using the infrared channel $(835 \mathrm{~nm})$ of the confocal scanning laser ophthalmoscope. The right eye was stimulated with a brief white flash (Olympus A16 flash unit, distance to eye $10 \mathrm{~cm}$ ) 5 seconds after the onset of the recording period. Pupil size at a given time was measured by fitting a circle to the inner margin of the iris in JPEG images time-coded relative to flash onset.

Immunohistochemistry. Sections from mouse thoracic spinal cord were processed for immunohistofluorescence as previously described (16). Primary antibodies recognized choline acetyltransferase (Chemicon International; AB114PF from goat, 1:250) or cFos (Santa-Cruz Biotechnology Inc.; SC-52 from rabbit, 1:500). Revelation was done using donkey anti-goat CY3 (1:400) and donkey anti-rabbit Alexa Fluor 488 (1:400) secondary antibodies. At least 5 sections per animal were analyzed $\left(P d c^{+/+}, n=6\right.$ mice; $P d c^{-/}, n=6$ mice).

Electrophysiology in sympathetic neurons. Neurons from SCG of male and female $P d c^{+/+}$and $P d c^{-/-}$mice were isolated by enzymatic digestion using trypsin I, collagenase I, and DNase I and plated on poly-D-lysine-coated coverslips. Electrophysiological recordings were performed at room temperature 1-3 days after cell dissociation. Nicotinic acetylcholine receptor currents as well as action potential firing were recorded upon perfusion with $10 \mu \mathrm{M}$ acetylcholine using the perforated patch clamp configuration. Membrane potentials were recorded using current clamp ( $\mathrm{I}=0$ mode) recording. The internal solution contained $10 \mathrm{mM} \mathrm{NaCl}, 130 \mathrm{mM} \mathrm{KCl}$, $1.0 \mathrm{mM} \mathrm{CaCl}_{2}, 0.5 \mathrm{mM} \mathrm{MgCl}_{2}, 3.0 \mathrm{mM} \mathrm{Mg}$-ATP, $0.3 \mathrm{mM} \mathrm{Na}_{2}$-GTP, $1.0 \mathrm{mM}$ EGTA, and $5 \mathrm{mM}$ HEPES, $\mathrm{pH}$ 7.4. Perforated patches were established by including $120 \mu \mathrm{g} / \mathrm{ml}$ amphotericin B in the pipette solution. The bath solution contained $135 \mathrm{mM} \mathrm{NaCl}, 5 \mathrm{mM} \mathrm{KCl}, 1.8 \mathrm{mM} \mathrm{CaCl}_{2}, 0.5 \mathrm{mM} \mathrm{MgCl}_{2}$, and $5 \mathrm{mM}$ HEPES, pH 7.4. Action potential firing after depolarization of cells by current injection was performed in the perforated patch clamp configuration. The internal solution contained $145 \mathrm{mM}$ potassium gluconate, $0.1 \mathrm{mM} \mathrm{CaCl}_{2}, 2.0 \mathrm{mM} \mathrm{MgCl}_{2}, 5 \mathrm{mM} \mathrm{Mg-ATP}, 0.3 \mathrm{mM}$ Tris-GTP, $1.0 \mathrm{mM}$ EGTA, and $5 \mathrm{mM}$ HEPES. Perforated patches were established by including $450 \mu \mathrm{g} / \mathrm{ml}$ amphotericin $\mathrm{B}$ in the pipette solution. The bath solution contained $126 \mathrm{mM} \mathrm{NaCl}, 3.0 \mathrm{mM} \mathrm{KCl}, 2.5 \mathrm{mM} \mathrm{CaCl}_{2}, 1.0 \mathrm{mM} \mathrm{MgCl}_{2}$, $26 \mathrm{mM} \mathrm{NaHCO}_{3}, 1.2 \mathrm{mM} \mathrm{NaH}_{2} \mathrm{PO}_{4}$, and $10 \mathrm{mM}$ glucose, $\mathrm{pH} 7.35$ (after the solution was gassed with $95 \% \mathrm{O}_{2}$ and $5 \% \mathrm{CO}_{2}$ ). $\mathrm{I}_{\mathrm{h}}$ current was measured after membrane hyperpolarization by current injection. $\mathrm{Na}^{+}$peak currents were evoked by membrane depolarization after voltage injection and normalized to cell capacitance to account for differences in cell size. For determination of $\mathrm{K}^{+}$conductance, $100 \mu \mathrm{M} \mathrm{Cd}^{2+}$ and $0.33 \mu \mathrm{M}$ tetrodotoxin were added to the superfusion buffer for blockade of $\mathrm{Ca}^{2+}$ and $\mathrm{Na}^{+}$ channels before voltage application. $\mathrm{K}^{+}$current integrals were calculated and normalized to cell capacitance.

\section{Human genetic analysis}

The study protocol was approved by the ethics committees at the Medical College of Wisconsin, Chicoutimi Hospital, Université du Québec a Chicoutimi (Chicoutimi, Quebec, Canada), and the Centre hospitalier de l'Université de Montréal. All participants gave written informed consent.

Populations. The FC population used in this study was a group of Caucasians from the Lac-St.-Jean region of Quebec that represent a unique founder population that arose from a limited number of families that settled in 1675 in a remote area north of Montreal. Families were ascertained by the presence of at least 1 sibling pair with hypertension and dyslipidemia. Sibship sizes ranged from 2 to 11 persons (mean 3.9; median 3 ) (44). The affected sib pair inclusion criteria were essential hypertension ( $\mathrm{SBP}>140 \mathrm{mmHg}$ and/or DBP $>90 \mathrm{mmHg}$ on 2 occasions or the use of antihypertensive medication), dyslipidemia (plasma cholesterol 5.2 $\mathrm{mmol} / \mathrm{l}$ and/or HDL cholesterol $0.9 \mathrm{mmol} / \mathrm{l}$ or the use of lipid-lowering medication), BMI $<35 \mathrm{~kg} / \mathrm{m}^{2}$, age $18-55$ years, and Catholic FC origin. Exclusion criteria were secondary hypertension, DBP $>110 \mathrm{mmHg}$ and the use of medication, diabetes mellitus, renal or liver dysfunction, malignancy, pregnancy, and substance abuse. Once the affected sibling pairs were selected, all first- and second-degree relatives over 18 years old were invited to participate in the study, independent of health status.

The AA population used in this study was recruited in Milwaukee, Wisconsin, USA (45). In brief, sibling pairs were selected if they were affected with hypertension (90 $\mathrm{mmHg}$ DBP or on antihypertensive therapy) and dyslipidemia (total cholesterol $>200 \mathrm{mg} / \mathrm{dl}$ or on lipid-lowering therapy), BMI $<35 \mathrm{~kg} / \mathrm{m}^{2}$, serum creatinine $<2.2 \mathrm{mg} / \mathrm{dl}$, no clinical evidence of secondary hypertension, no diabetes (fasting blood glucose $>140 \mathrm{mg} / \mathrm{dl}$ or on insulin or oral hypoglycemic agents), no malignancy, no pregnancy, no substance abuse, and no liver disease.

Phenotype procedures. All blood pressure measurements were performed after blood pressure medication was discontinued for at least 1 week. The post math blood pressure phenotypes were measured with a Dinamap monitoring system and represent SBPs and DBPs at the 8-minute point 
following the conclusion of a verbal math test lasting 2 minutes. The standing blood pressure phenotypes were also measured with a Dinamap system and represent SBPs and DBPs 4 minutes after a postural change from supine to standing. The average wake blood pressure phenotypes were the average SBP and DBP while an individual was awake during a 24-hour blood pressure monitoring session determined by an Accutracker ambulatory blood pressure monitor that performed measurements every 20 minutes during the day (5:00 am-11:00 pm) and every 45 minutes during the night (11:00 pm-5:00 am).

LD estimation. Pairwise LD was estimated using the D statistic, and haplotype blocks were designated using the confidence interval method by Gabriel et al. (46). All LD and haplotype calculation and visualization were conducted using Haploview (version 3.2) (19).

Association analysis. The QTDT program was used for the quantitative family-based single SNP and SNP haplotype association analysis (18). A variance component method approach for association was used incorporating both genetic and environmental factors. $P$ values were adjusted for age and gender as well as phenotype-specific covariates. In the FC population, the following measurements were included as covariates: renal disease and diabetes status for DBP and SBP after the math test, diabetes status and plasma creatinine for SBP after the math test, plasma insulin for standing DBP, standing plasma epinephrine and renin, hip circumference, 2-hour urinary lithium for average waking DBP, and 2-hour urinary lithium for average waking SBP. In the AA population, covariates were as follows: aldosterone/renin ratio and plasma potassium for DBP and SBP after the math test, aldosterone/renin ratio and total body water for standing DBP and SBP, and average waking DBP and SBP. Haplotype for association analyses were determined using the Genehunter program (47), and subsequent family-based association analysis was performed using the quantitative transmission disequilibrium test (QTDT). In order to control for multiple testing, $P$ values were adjusted using the FDR method by Benjamini and Hochberg (20), taking into account as a conservative estimate the number of tested phenotypes and all SNPs being independent (Proc
MULTTEST, SAS 9.1). A combined $P$ value was calculated using Fisher's combined probability test for independent observations.

\section{Statistics}

Hemodynamic, histological and catecholamine data were analyzed using ANOVA followed by Bonferroni post-hoc tests or 2-tailed Student's $t$ test, respectively. A $P$ value less than 0.05 was considered statistically significant. Results are shown as means \pm SEM.

\section{Acknowledgments}

We thank Kerstin Hadamek (University of Würzburg), Günther Schütz and Daniela Nebenius-Oosthuizen (DKFZ, Heidelberg, Germany) for their assistance with ES cell culture, and Reinhard Wölfel (University of Würzburg) and Eduardo Moura (University of Porto) for assistance with catecholamine measurements. This study was supported in part by grants from the Deutsche Forschungsgemeinschaft (to L. Hein, M.J. Lohse, M.W. Seeliger, X. Zong, and M. Biel), the Excellence Initiative of the German Federal and State Governments (grant EXC 294), the American Heart Association (to M.D. Harrison), and the NHLBI (grant HL082798, to P. Hamet, T.A. Kotchen, H.J. Jacob, A.W. Cowley Jr., and U. Broeckel).

Received for publication May 19, 2009, and accepted in revised form September 30, 2009.

Address correspondence to: Lutz Hein, Institute of Experimental and Clinical Pharmacology and Toxicology, University of Freiburg, Albertstrasse 25, 79104 Freiburg, Germany. Phone: 49761-2035314; Fax: 49-761-2035318; E-mail: lutz.hein@pharmakol. uni-freiburg.de. Or to: Ulrich Broeckel, Human and Molecular Genetics, Medical College of Wisconsin, 8701 Watertown Plank Rd., Milwaukee, Wisconsin 53226, USA. Phone: (414) 955-2369; Fax: (414) 456-6516; E-mail: broeckel@mcw.edu.
1. Kearney, P.M., et al. 2005. Global burden of hypertension: analysis of worldwide data. Lancet. 365:217-223

2. Janeway, T.C. 1907. The clinical study of blood pressure. D. Appleton \& Co. New York, New York, USA. 300 pp.

3. Cowley, A.W., Jr. 2006. The genetic dissection of essential hypertension. Nat. Rev. Genet. 7:829-840.

4. Esler, M. 2000. The sympathetic system and hypertension. Am. J. Hypertens. 13:99S-105S.

5. Guyenet, P.G. 2006. The sympathetic control of blood pressure. Nat. Rev. Neurosci. 7:335-346.

6. Rockman, H.A., Koch, W.J., and Lefkowitz, R.J. 2002. Seven-transmembrane-spanning receptors and heart function. Nature. 415:206-212.

7. Wirth, A., et al. 2008. G12-G13-LARG-mediated signaling in vascular smooth muscle is required for salt-induced hypertension. Nat. Med. 14:64-68.

8. Tang, K.M., et al. 2003. Regulator of G-protein signaling-2 mediates vascular smooth muscle relaxation and blood pressure. Nat. Med. 9:1506-1512.

9. Bauer, P.H., et al. 1992. Phosducin is a protein kinase A-regulated G-protein regulator. Nature. 358:73-76.

10. Gaudet, R., Bohm, A., and Sigler, P.B. 1996. Crystal structure at 2.4 angstroms resolution of the complex of transducin betagamma and its regulator, phosducin. Cell. 87:577-588.

11. Humrich, J., et al. 2005. Phosducin-like protein regulates G-protein betagamma folding by interaction with tailless complex polypeptide-1alpha: dephosphorylation or splicing of PhLP turns the switch toward regulation of $\mathrm{G}$ beta gamma folding. J. Biol. Chem. 280:20042-20050.

12. Knol, J.C., Engel, R., Blaauw, M., Visser, A.J., and van Haastert, P.J. 2005. The phosducin-like protein PhLP1 is essential for G beta gamma dimer formation in Dictyostelium discoideum. Mol. Cell. Biol. 25:8393-8400

13. Lukov, G.L., Hu, T., McLaughlin, J.N., Hamm, H.E., and Willardson, B.M. 2005. Phosducin-like protein acts as a molecular chaperone for $\mathrm{G}$ protein beta gamma dimer assembly. EMBOJ. 24:1965-1975.

14. Zhu, X., and Craft, C.M. 1998. Interaction of phosducin and phosducin isoforms with a $26 \mathrm{~S}$ proteasomal subunit, SUG1. Mol. Vis. 4:13.

15. Roseboom, P.H., et al. 1998. Natural melatonin 'knockdown' in C57BL/6J mice: rare mechanism truncates serotonin N-acetyltransferase. Brain Res. Mol. Brain Res. 63:189-197.

16. Kaufling, J., Veinante, P., Pawlowski, S.A., FreundMercier, M.J., and Barrot, M. 2009. Afferents to the GABAergic tail of the ventral tegmental area in the rat. J. Comp. Neurol. 513:597-621.

17. Minson, J.B., Arnolda, L.F., and Llewellyn-Smith, I.J. 2002. Neurochemistry of nerve fibers apposing sympathetic preganglionic neurons activated by sustained hypotension. J. Comp. Neurol. 449:307-318.

18. Abecasis, G.R., Cardon, L.R., and Cookson, W.O. 2000. A general test of association for quantitative traits in nuclear families. Am. J. Hum. Genet. 66:279-292.

19. Barrett, J.C., Fry, B., Maller, J., and Daly, M.J. 2005. Haploview: analysis and visualization of LD and haplotype maps. Bioinformatics. 21:263-265.

20. Benjamini, Y., and Hochberg, Y. 1995. Controlling the false discovery rate: a practical and powerful approach to multiple testing. J. R. Stat. Soc. Series B Stat. Methodol. 57:289-300.
21. Saxena, R., et al. 2007. Genome-wide association analysis identifies loci for type 2 diabetes and triglyceride levels. Science. 316:1331-1336.

22. Wellcome Trust Case Control Consortium. 2007. Genome-wide association study of 14,000 cases of seven common diseases and 3,000 shared controls. Nature. 447:661-678.

23. Sokolov, M., et al. 2004. Phosducin facilitates lightdriven transducin translocation in rod photoreceptors. Evidence from the phosducin knockout mouse. J. Biol. Chem. 279:19149-19156.

24. Craft, C.M., Lolley, R.N., Seldin, M.F., and Lee, R.H 1991. Rat pineal gland phosducin: cDNA isolation, nucleotide sequence, and chromosomal assignment in the mouse. Genomics. 10:400-409.

25. Goto, M., Oshima, I., Tomita, T., and Ebihara, S. 1989. Melatonin content of the pineal gland in different mouse strains. J. Pineal Res. 7:195-204.

26. Ritz, E. 2007. Total cardiovascular risk management. Am. J. Cardiol. 100:53J-60J.

27. Lewington, S., Clarke, R., Qizilbash, N., Peto, R., and Collins, R. 2002. Age-specific relevance of usual blood pressure to vascular mortality: a metaanalysis of individual data for one million adults in 61 prospective studies. Lancet. 360:1903-1913.

28. Antman, E.M., et al. 2007. Use of nonsteroidal antiinflammatory drugs: an update for clinicians: a scientific statement from the American Heart Association. Circulation. 115:1634-1642.

29. Aw, T.J., Haas, S.J., Liew, D., and Krum, H. 2005. Meta-analysis of cyclooxygenase- 2 inhibitors and their effects on blood pressure. Arch. Intern. Med. 165:490-496.

30. Dinchuk, J.E., et al. 1995. Renal abnormalities and 
an altered inflammatory response in mice lacking cyclooxygenase II. Nature. 378:406-409.

31. Morham, S.G., et al. 1995. Prostaglandin synthase 2 gene disruption causes severe renal pathology in the mouse. Cell. 83:473-482.

32. Yang, T., et al. 2005. Influence of genetic background and gender on hypertension and renal failure in COX-2-deficient mice. Am. J. Physiol. Renal Physiol. 288:F1125-F1132.

33. Kohara, K., et al. 2008. Identification of hypertension-susceptibility genes and pathways by a systemic multiple candidate gene approach: the millennium genome project for hypertension. Hypertens. Res. 31:203-212.

34. Victor, R.G., and Shafiq, M.M. 2008. Sympathetic neural mechanisms in human hypertension. Curr. Hypertens. Rep. 10:241-247.

35. Hein, L., Barsh, G.S., Pratt, R.E., Dzau, V.J., and Kobilka, B.K. 1995. Behavioural and cardiovascular effects of disrupting the angiotensin II type-2 receptor in mice. Nature. 377:744-747.

36. Klenk, C., Humrich, J., Quitterer, U., and Lohse,
M.J. 2006. SUMO-1 controls the protein stability and the biological function of phosducin. J. Biol. Chem. 281:8357-8364.

37. Davis, B.J., et al. 1999. Anovulation in cyclooxygenase-2-deficient mice is restored by prostaglandin E2 and interleukin-1beta. Endocrinology. 140:2685-2695.

38. Gilsbach, R., Kouta, M., Bonisch, H., and Bruss, M. 2006. Comparison of in vitro and in vivo reference genes for internal standardization of real-time PCR data. Biotechniques. 40:173-177.

39. Stolle, K., et al. 2005. Cloning, cellular localization, genomic organization, and tissue-specific expression of the TGFbeta1-inducible SMAP-5 gene. Gene. 351:119-130.

40. Gilsbach, R., et al. 2007. Heterozygous alpha(2C)adrenoceptor-deficient mice develop heart failure after transverse aortic constriction. Cardiovasc. Res. 75:728-737.

41. Brede, M., et al. 2001. Vascular hypertrophy and increased P70S6 kinase in mice lacking the angiotensin II AT(2) receptor. Circulation. 104:2602-2607.
42. Brede, M., et al. 2003. Differential control of adrenal and sympathetic catecholamine release by alpha 2-adrenoceptor subtypes. Mol. Endocrinol. 17:1640-1646.

43. Hein, L., Altman, J.D., and Kobilka, B.K. 1999. Two functionally distinct alpha2-adrenergic receptors regulate sympathetic neurotransmission. Nature. 402:181-184.

44. Hamet, P., et al. 2005. Quantitative founder-effect analysis of French Canadian families identifies specific loci contributing to metabolic phenotypes of hypertension. Am. J. Hum. Genet. 76:815-832.

45. Kotchen, T.A., et al. 2002. Identification of hypertension-related QTLs in African American sib pairs. Hypertension. 40:634-639.

46. Gabriel, S.B., et al. 2002. The structure of haplotype blocks in the human genome. Science. 296:2225-2229.

47. Kruglyak, L., Daly, M.J., Reeve-Daly, M.P., and Lander, E.S. 1996. Parametric and nonparametric linkage analysis: a unified multipoint approach. Am. J. Hum. Genet. 58:1347-1363. 